This PDF is a selection from a published volume from the National Bureau of Economic Research

Volume Title: Health and Labor Force Participation over the Life Cycle: Evidence from the Past

Volume Author/Editor: Dora L. Costa, editor

Volume Publisher: University of Chicago Press

Volume ISBN: 0-226-11618-2

Volume URL: http://www.nber.org/books/cost03-1

Conference Date: February 2-3, 2001

Publication Date: January 2003

Title: The Effect of Hernias on the Labor Force Participation of Union Army Veterans

Author: Chen Song, Louis Nguyen

URL: http://www.nber.org/chapters/c9635 


\title{
The Effect of Hernias on the Labor Force Participation of Union Army Veterans
}

\author{
Chen Song and Louis L. Nguyen
}

\subsection{Introduction}

The health status of the elderly and its impact on labor supply and on the quality of life before and after retirement is an empirical issue that may be best addressed by high-quality panel data, that is, data that contain comprehensive health and work information over time. One of the most frequently used contemporary data sets for research in this area is the Health and Retirement Study. Other popular contemporary data sets include the Retirement History Longitudinal Survey, the National Health Interview Survey, and the National Health and Nutrition Examination Survey. ${ }^{1}$

The health information recorded in many contemporary data sets suffers two major shortcomings. First, the overall measurement of health is a dichotomous indicator of self-assessed health status derived by classifying responses of "excellent," "very good," "good," "fair," and "poor." Second, the doctor-diagnosed conditions are coded as zero-one dummy variables, with

Chen Song is an economist at Resolution Economics, LLC, and a senior investigator at the Center for Population Economics at University of Chicago, Graduate School of Business. Louis L. Nguyen is a chief surgery resident with Barnes-Jewish Hospital at Washington University in St. Louis and a senior investigator for the Center for Population Economics.

We thank Robert Fogel, Max Henderson, Tayatat Kanjanapipatkul, Jibum Kim, Chulhee Lee, Mario Sánchez, Peter Viechnicki, and other conference participants for helpful comments. We owe special gratitude to Peter Blanck for being our discussant at the conference, and to Dora Costa for providing us with many insightful suggestions. We are responsible for all the errors in the paper.

1. See, for example, Blau and Gilleskie (2001), Bound et al. (1999), Chan and Stevens (2001), Coile and Gruber (2000a), Costa (2002), Dwyer and Mitchell (1999), Gustman and Steinmeier (2000), and Mitchell and Phillips (2000). 
a one indicating the prevalence of a certain condition, and a zero indicating no such condition. ${ }^{2}$

Bound et al. (1999) identifies four potential problems with self-reported global health, the main problem being that the judgments are subjective and that responses may not be independent of the labor market outcomes an investigator hopes to explain, thereby introducing endogeneity into the explanatory variable. The zero-one condition dummies provide a more objective indicator of health status. However, those dummy variables do not account for the severity of the conditions experienced, so that all conditions are weighted equally. Comorbidity, or the prevalence of two or more conditions, does alleviate the lack of severity measure between conditions by purging away the correlation between any two of them, although severity within each condition is still left unmeasured.

This paper focuses on the labor supply implications of hernias, a specific chronic disability that can be extremely debilitating. We examine the retirement behavior of 3,406 older men. The Union Army (UA) health data in the Surgeons' Certificates (SC) file are longitudinal, because veterans could apply for the UA pension several times and be examined at different points in their lives. Compared to the contemporary health data, they are more comprehensive because symptoms of each disability are documented, which makes it possible for researchers to quantify severity.

A common approach taken by other projects that use the UA files is the inclusion of several zero-one disease indicators in the group of explanatory variables (e.g., Costa 2002). In comparison to those approaches, our investigation is more focused. We transcribe descriptions of hernia symptoms such as size, subtype, location, and morbidity into measures that we incorporate into a regression analysis. We study the labor participation implication using those measures, in addition to using the zero-one hernia dummy variable. Since data collection has become more sophisticated and precise over time, our methodology demonstrates one way of utilizing large-scale medical information. A more ambitious next step will be to construct a health composite index from all the available severity measures within each disability, as well as across all disabilities. This composite index will be superior to the traditional aggregate of zero-one disability dummy variables and will improve prediction of the role of health in economic behavior.

The organization of the rest of the paper is as follows: Section 10.2 provides a medical background for the history and the treatment of hernias; section 10.3 describes the UA sample; section 10.4 offers an empirical framework; section 10.5 analyzes the results; and section 10.6 concludes.

2. See, for example, Blau and Gilleskie (2001), Costa (2002, 2003), and Mitchell and Phillips (2000). 


\subsection{Medical Background}

Although humans have been afflicted with groin hernias throughout history, a thorough understanding of the anatomy of the inguinal canal was not achieved until the early nineteenth century. During this time, cadaver dissections and clinical studies led to publication of anatomic atlases and treatises on the subject of groin hernias (Rutkow 1998). Despite the greater understanding of anatomy, surgical repair of hernias at the time was troubled by recurrence of the hernia. Thus, treatment of hernias was limited to the use of trusses, while surgery was performed in cases of hernia strangulation. Since then, improvements in anesthesia, surgical technique, sutures, and prosthetic materials have led to earlier surgical intervention and better clinical outcomes.

\subsubsection{Prevalence}

A hernia is an abnormal protrusion of organ or tissue out of the cavity in which it normally lies and into another space or potential space. Generally, the term refers to the more common groin or inguinal hernia, although other types exist and are described by their anatomic locations: epigastric, hiatal, obturator, umbilical, and ventral. Unfortunately, the epidemiology of groin hernias is not well defined. Historically, it was estimated that 4.6 percent of the entire population of the United States was afflicted with hernias (Iason 1941). A more recent survey based on clinical exams revealed that men aged twenty-five or older had a hernia prevalence rate (excluding repaired hernias) of 18 percent and a lifetime prevalence rate (inclusive of repaired hernias) of 24 percent (Abramson et al., 1978). In contrast, selfreported information from insurance enrollment questionnaires estimated the prevalence rate of men aged twenty-five to thirty-four to be 1 percent, but higher in men aged thirty-five to forty-four (1.8 percent), aged forty-five to fifty-four (2.2 percent), and aged fifty-five to sixty-four (3.9 percent; Rubenstein, Beck, and Lohr 1983). While some differences between the rates may be due to underestimation from self-reported surveys, the differences are large and representative of the disparity in the field.

\subsubsection{Distribution}

With respect to gender distribution, it is believed that the prevalence rate of groin hernias is higher in men than in women, although the exact ratio is not well known. An early-twentieth-century report from New York Hospital for Ruptured and Crippled reported at 3.1:1.0 male-to-female ratio (Coley, Keen, and DaCosta 1910). A more recent study from Henry Ford Hospital in Detroit showed a 12:1 male-female ratio (Ponka 1980). A review of the hernia repairs performed over the last fifty years at Shouldice Hospital in Toronto revealed a 21:1 male-female ratio (Welsh and Alexander 1993). The relative 
frequency of groin hernias compared to other hernias is also not well known. Representative data from the Henry Ford Hospital showed that in men, inguinal hernias comprised 81 percent of all hernias, while femoral ( 3 percent), combinations of inguinal/femoral ( 8 percent), umbilical ( 2 percent), incisional (4 percent), hiatal ( 2 percent), and epigastric ( 1 percent) comprised the rest. For women, the ratios were inguinal (35 percent), femoral (11 percent, combination inguinal/femoral ( 3 percent), umbilical (17 percent), incisional (18 percent), hiatal (15 percent), and epigastric (3 percent; Ponka 1980).

\subsubsection{Natural history}

Patients with hernias present a wide range of symptoms. Some patients are asymptomatic and have elective surgery to prevent future complications; others present with strangulated hernias and require emergency surgery. For most patients, a protuberant hernia is discomforting, but heavy lifting or straining can cause moderate or severe pain. This discomfort leads to avoidance of heavy labor and strenuous exercise unless the hernia can be retained with a truss or surgically corrected. Hernias also have a possibility of developing complications such as incarceration (inability to be reduced) or strangulation (in which vascular supply to herniated bowel is compromised).

\subsubsection{Treatment}

Although the anatomy of the human inguinal region was well demonstrated in the early nineteenth century by surgeons and anatomists such as Astley Cooper (1804, 1807), Franz Hesselbach (1806, 1814), and Antonio Scarpa $(1809,1821)$, surgical repair of hernias was complicated by frequent recurrence (Bull 1890). Thus, early remedies for hernias were nonsurgical and included the use of external binding bandages to prevent protrusion of hernias. Later refinements led to the use of trusses, which were formed binders capable of more direct pressure on the hernia site. Young patients could expect their hernias to be "cured" if the truss was worn regularly, whereas older patients could expect temporary relief and were dependent on the truss indefinitely (Cooper 1804). Most of the modern experience with trusses comes from the United Kingdom, where the access to surgery is reduced compared to other industrialized nations. Partial or complete control of the hernia was achieved in only 31 percent of patients (Law and Trapnell 1992). However, surveys have found that about 60 percent of truss wearers did not consult a physician before purchasing a truss (Cheek, Williams, and Farndon 1995). Furthermore, many trusses are poorly fitted, resulting in failure to hold the hernia or causing undue discomfort. Thus, the true efficacy of trusses has not been well defined.

In 1889, William Halsted and Edoardo Bassini (Halstead 1889; Bassini 1889 ) independently reported a hernia repair that reconstructed the inguinal floor by apposing the conjoined tendon with the posterior rim of Poupart's ligament. Both reported dramatically reduced recurrence rates (3 
to 4 percent over four years) with their procedures compared to other methods available at the time. Later refinements in hernia repair by McVay (1948) and shouldice (Shearburn and Myers 1969) led to further improvements, yielding recurrence rates of less than 1 percent. The traditional dogma of hernia repair was revised when Lichtenstein published his experience with 6,321 cases of hernia repair. He believed that traditional repair methods using sutures were anatomically rigid, and instead supported the use of a prosthetic mesh to buttress the weak tissues. His patients had low recurrence rates $(0.7$ percent) and lower requirements for pain medications postoperatively (Lichenstein 1987). The recent development of laparoscopic hernia repair has allowed patients with bilateral hernias to have them fixed in one operation rather than two.

While the therapy for hernias has evolved, the method of diagnosis and natural history has not changed much since hernias were anatomically understood in the early nineteenth century. This characteristic of hernias permits us to study the effects of hernias on labor participation during a period when most hernias were not repaired electively. This unique look at the effects of hernias without intervention also provides insight into the beneficial effects of modern hernia therapy.

\subsection{Data}

The data used in this study were from Civil War records stored at the United States National Archives. A random sample of 39,616 white male recruits with enlistment papers (the Military Service Records file) was drawn from the National Archives, representing 331 companies mustered into the UA during the Civil War (Center for Population Economics [CPE] 1998). Approximately 85 percent of those recruits, or 33,674 men, were also linked to the Pension Bureau data set (the Pension Records file). At the time of this paper we were able to obtain records on 28,530 recruits from the Pension Records file. ${ }^{3}$

The bulk of the health information came from the Surgeons' Certificates file. This file stores details of the physical examinations of 16,713 pension applicants. The Pension Bureau surgeons conducted those examinations. An examination consisted of an inspection of the general organ systems as well as an investigation of active medical problems. Components of the handwritten exam entries were transcribed into "disease variables" that captured the essential information about the exam findings.

Table 10.1 presents the data availability under each variable of interest to

3. Data from Wisconsin, Indiana, New Mexico, and California were still being cleaned and were not included in the Military Records file. In addition to data from those four states, data from New Jersey were not included in the Pension Records file. Moreover, a prior pilot sample of twenty companies with the same geographical composition of recruits as the Military Records file was missing. 


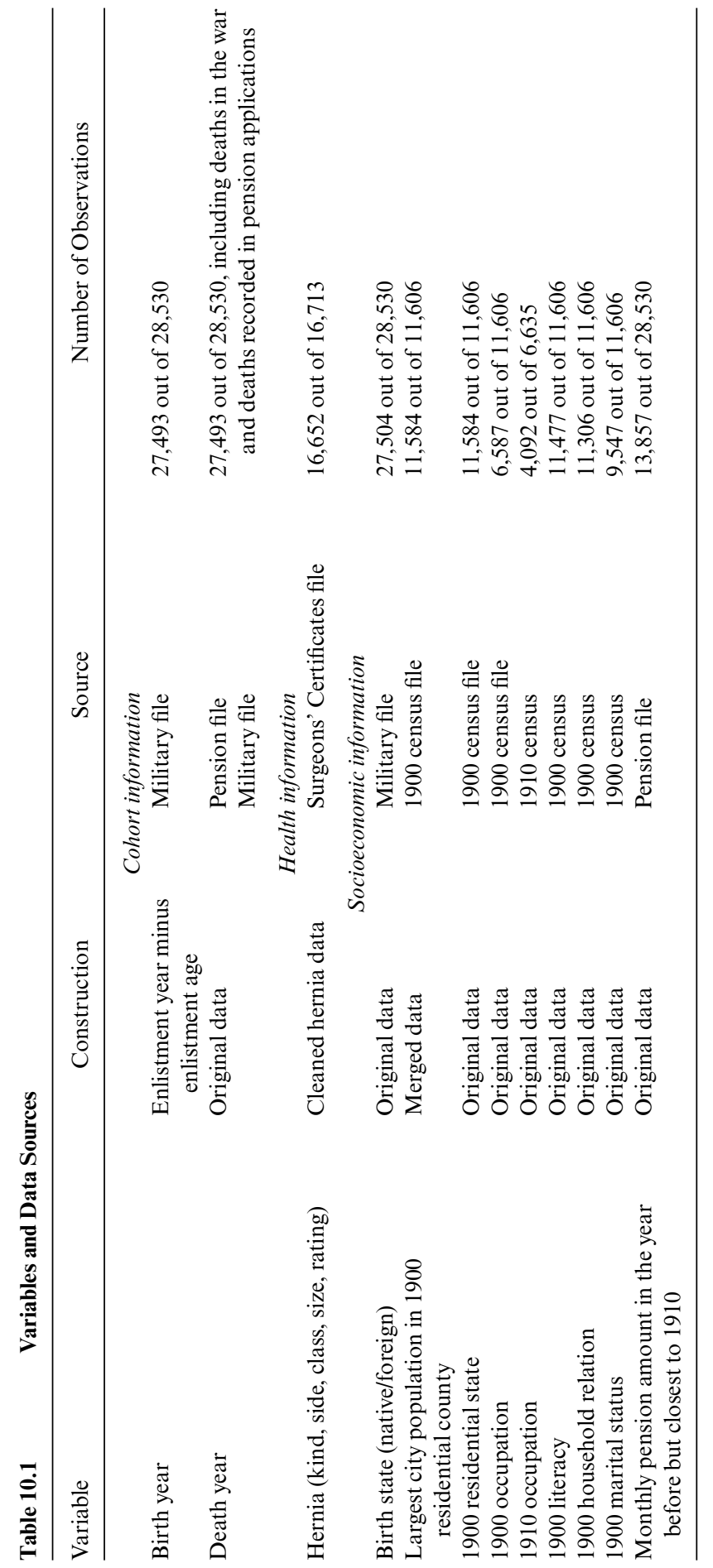


our study. We group the variables into three categories pertaining to cohort, health, and socioeconomic status. While the cohort information is easy to obtain, ${ }^{4}$ a fair amount of work is involved in the standardization of the hernia variable, as well as in the categorization of occupations. We provide a detailed explanation of how we construct hernia measures to fit the purpose of our study in the appendix. We give some examples in table 10.2 to illustrate the standardization process.

Table 10.3 summarizes the number of cases from the last step of transcription for 2,350 hernia patients and 6,395 patient-exam pairs in the Surgeons' Certificates file. The most common hernia subtype is hernia at the inguinal region, which covers 90 percent of the patients. The less usual, but representative subtypes are: ventral, where a hernia is abdominal incisional: umbilical, where a hernia protrudes through the abdominal wall under the skin at the umbilicus; and femoral, where a hernia passes through the femoral canal. Two rare subtypes are an epigastric hernia, which is a hernia protruding through the linea alba above the navel, and a hiatal hernia, which is a hernia of the stomach through the diaphragm.

Under the category "hernia morbidity and truss efficacy," truss effective refers to a hernia whose impact could be minimized by the wearing of a support, such as a truss. This group is considered the least morbid. The next morbid group was a reducible hernia, in which the contents of the protrusion could be returned to their normal location. Eighty-six percent of the patients had either truss-effective or reducible hernias. If wearing a truss did not have any effect at all, a hernia became more morbid than the previous two groups. A hernia is described as "inflamed" where there are in fact signs of inflammation. Furthermore, when a hernia is not irreducible, it is "incarcerated." An incarcerated hernia develops into a "strangulated" hernia if the circulation is compromised (Spraycar 1995, 788-90). A patient with a single hernia is less disabled than one with double hernias, and disability increases with the size of a hernia. Group proportions under each diagnostic category are comparable with those from other populations.

We use hernia ratings to estimate the overall degree of disability from having a hernia or hernias. The denominator of the rating variable is the maximum severity of hernias, and the numerator is the severity of hernias observed in a patient. Higher hernia ratings correspond to more severe hernias. Table 10.4 shows the distribution of surgeons' hernia ratings, ranging from 0.0000 to 1.0000 . Out of the 6,395 hernia patient-exam pairs, we have ratings information for 5,026 of them. As a chronic condition, hernia was

4. When the year of birth (YOB) cannot be found from the Pension Records file, the year was inferred by subtracting the age at enlistment from the year of enlistment. Among records with YOB, age of birth, and year of enlistment, the distribution of the differential between the calculated YOB and the recorded YOB in the pension data centered at zero, with the majority of the mass clustered between -1 and 1 year (Song 1999). Year of death is useful, because many recruits still had several years to live after their last recorded medical exams. 
Table 10.2

Examples of Transcription of Hernia Diagnoses

\begin{tabular}{|c|c|c|}
\hline $\begin{array}{l}\text { Original Description Appearing } \\
\text { in Surgeons' Certificates }\end{array}$ & $\begin{array}{l}\text { Transcribed Answer } \\
\text { Classes (AC) }\end{array}$ & $\begin{array}{c}\text { Transcribed Middle } \\
\text { Modifiers (MM) }\end{array}$ \\
\hline \multicolumn{3}{|l|}{ Hernia subtype } \\
\hline 2 complete hernias & Inguinal & Bilateral, complete \\
\hline Right abdominal rupture & Ventral & Right \\
\hline Directly above umbilicus & Umbilical & None \\
\hline Complete right femoral hernia & Femoral & Right \\
\hline Hernia linea alba & Epigastric & None \\
\hline Rupture of stomach & Hiatal & None \\
\hline Complete hernia & Nonspecified & None \\
\hline \multicolumn{3}{|l|}{ Hernia morbidity and truss efficacy } \\
\hline $\begin{array}{l}\text { Left tumor descend into scrotum } \\
\text { if not held by truss }\end{array}$ & Truss effective & Left \\
\hline $\begin{array}{l}\text { Left hernia requires more force } \\
\text { than right to be reduced }\end{array}$ & Reducible & Bilateral \\
\hline No bandage is of any use & Truss not effective & None \\
\hline Inflamed & Inflamed & None \\
\hline $\begin{array}{l}\text { Adhesions prevent its full } \\
\text { reducibility }\end{array}$ & Incarcerated & None \\
\hline Left hernia strangulated & Strangulated & Left \\
\hline Hernia is not inflamed & Nonspecified & None \\
\hline Not aneurysm & Nonclassified & None \\
\hline \multicolumn{3}{|l|}{ Hernia size } \\
\hline Left three cent pieces & Less than $1^{\prime \prime}$ & Left \\
\hline Man's two fingers & $1^{\prime \prime}$ & None \\
\hline Quail egg & $2^{\prime \prime}$ & None \\
\hline Right femoral 3 by 2 inches & $3^{\prime \prime}$ & Right \\
\hline Large grapefruit & $4^{\prime \prime}$ & None \\
\hline Pineapple & $6^{\prime \prime}$ & None \\
\hline Man's two fists & $8^{\prime \prime}$ & None \\
\hline Right very large & Nonspecified & Right \\
\hline Veins 3 times normal & Nonclassified & None \\
\hline \multicolumn{3}{|l|}{ Hernia location } \\
\hline MM bilateral & Double & \\
\hline MM right & Single & \\
\hline MM left & Single & \\
\hline
\end{tabular}

given high ratings. The average rating is 0.4286 , which is a little below half of total disability. ${ }^{5}$ Over a third of the cases corresponded to at least half disability, and over a quarter of the cases corresponded to at least a quarter disability. In the sections that follow, we will refer to the hernia disability ratings as the major health indicator.

For those 28,530 recruits in the pension data, 9,114 were linked to the 1900 census, henceforth referred to as the 1900 census file, and 5,182 were

5. For purposes of the pension rating system, total disability was defined by the Pension Bureau as "a total disability for the performance of manual labor requiring severe and continuous exertion" (Glasson 1918, 131). 
Table 10.3

Hernia Severity (by diagnostic category) Where an Observation Is a Patient-Exam Pair

\begin{tabular}{|c|c|c|}
\hline Diagnostic Category & Number of Cases & Percentage of Total \\
\hline Hernia subtype & 5,440 & \\
\hline Inguinal & 4,902 & 90.1 \\
\hline \multicolumn{3}{|l|}{ More unusual subtypes } \\
\hline Ventral & 226 & 4.2 \\
\hline Umbilical & 146 & 2.7 \\
\hline Femoral & 52 & 1.0 \\
\hline Epigastric & 1 & 0.0 \\
\hline Hiatal & 2 & 0.0 \\
\hline Nonspecified or nonclassified & 111 & 2.0 \\
\hline Hernia morbidity and truss efficacy & 4,610 & \\
\hline Truss effective & 1,335 & 29.0 \\
\hline Reducible & 2,609 & 56.6 \\
\hline \multicolumn{3}{|l|}{ Higher morbidity } \\
\hline Truss not effective & 319 & 6.9 \\
\hline Inflamed & 2 & 0.0 \\
\hline Incarcerated & 137 & 3.0 \\
\hline Strangulated & 15 & 0.3 \\
\hline Nonspecified or nonclassified & 193 & 4.1 \\
\hline Hernia location & 4,942 & \\
\hline \multicolumn{3}{|l|}{ Single hernia } \\
\hline Right hernia & 2,437 & 49.3 \\
\hline Left hernia & 1,642 & 33.2 \\
\hline Double hernias & 594 & 12.0 \\
\hline Nonspecified or nonclassified & 269 & 5.5 \\
\hline Hernia size & 4,017 & \\
\hline Less than $1^{\prime \prime}$ & 108 & 2.7 \\
\hline $1-2^{\prime \prime}$ & 577 & 14.4 \\
\hline $2-3^{\prime \prime}$ & 1,143 & 28.5 \\
\hline $3-4^{\prime \prime}$ & 746 & 18.6 \\
\hline $4^{\prime \prime}$ and up & 800 & 19.9 \\
\hline Nonspecified or nonclassified & 643 & 16.0 \\
\hline
\end{tabular}

linked to the 1910 census, henceforth referred to as the 1910 census file. ${ }^{6} \mathrm{We}$ exclude veterans who were retired by 1900 . This leaves us with 3,406 individuals. Out of those veterans, 1,848 men survive the data merge with the Surgeons' Certificates file, among which 1,796 have nonmissing information on monthly pension awards. By 1900, 257 had hernias. Ten years later, an additional eighty-nine men contracted this disability, making the total number of hernia patients 346 by 1910 .

There are 1,558 men $(3,406-1,848)$ without a surgeon's record. If they

6. The key to a successful link is the presence of "soundexes" for the census constructed by a commercial genealogist. The soundexes can map a recruit's name to a possible candidate in the census given the location of the recruit during the census year. Also, the Civil War enrollment lists may give addresses that would aid in the location of individuals not found through the soundexes. 
Table 10.4 Hernia Severity (by ratings) where an Observation Is a Patient-Exam Pair

\begin{tabular}{|c|c|c|c|}
\hline Hernia Rating & Number of Cases & Percentage of Total & Cumulative $(\%)$ \\
\hline 0.0000 & 295 & 5.9 & 5.9 \\
\hline 0.0556 & 4 & 0.1 & 5.9 \\
\hline 0.1111 & 286 & 5.7 & 11.6 \\
\hline 0.1250 & 6 & 0.1 & 11.8 \\
\hline 0.1429 & 2 & 0.0 & 11.8 \\
\hline 0.1667 & 29 & 0.6 & 12.4 \\
\hline 0.2000 & 7 & 0.1 & 12.5 \\
\hline 0.2222 & 632 & 12.6 & 25.1 \\
\hline 0.2500 & 88 & 1.8 & 26.8 \\
\hline 0.2778 & 10 & 0.2 & 27.0 \\
\hline 0.3333 & 607 & 12.1 & 39.1 \\
\hline 0.3750 & 3 & 0.1 & 39.2 \\
\hline 0.3889 & 2 & 0.0 & 39.2 \\
\hline 0.4286 & 1 & 0.0 & 39.2 \\
\hline 0.4444 & 917 & 18.2 & 57.5 \\
\hline 0.5000 & 310 & 6.2 & 63.6 \\
\hline 0.5556 & 1,017 & 20.2 & 83.9 \\
\hline 0.5882 & 1 & 0.0 & 83.9 \\
\hline 0.6111 & 3 & 0.1 & 83.9 \\
\hline 0.6250 & 7 & 0.1 & 84.1 \\
\hline 0.6316 & 1 & 0.0 & 84.1 \\
\hline 0.6667 & 424 & 8.4 & 92.5 \\
\hline 0.7500 & 58 & 1.2 & 93.7 \\
\hline 0.7778 & 235 & 4.7 & 98.4 \\
\hline 0.8333 & 12 & 0.2 & 98.6 \\
\hline 0.8824 & 1 & 0.0 & 98.6 \\
\hline 0.8889 & 17 & 0.3 & 99.0 \\
\hline 0.9444 & 39 & 0.8 & 99.7 \\
\hline 1.000 & 12 & 0.2 & 100.0 \\
\hline Number of observations & 5,026 & 100 & 100 \\
\hline
\end{tabular}

were at risk to be linked, they fall into two categories: The first category consists of men who applied early because of severe war disabilities. The second category consists of men who applied late on the grounds of old age, and thus were never examined. On average, men who did not have a surgeon's record were in better health. Men who had a surgeon's record had at least one disability. A frequency of the application year by linkage to the Surgeons' Certificates file reveals that for those not linked, 617 of them had nonmissing application-year information: The mean application year is 1889 , the earliest application year is 1863 , and the latest application year is 1924. For those linked, 1,843 had nonmissing application-year information: The mean application year is 1885 , the earliest is 1861 , and the latest is 1912. Therefore, it is likely that men without surgeons' records were healthier and they tended to apply later. 
We use two samples to study the effect of hernias on retirement. The first sample has 1,796 men with nonmissing pension award who are linked to the Surgeons' Certificates file. We compare retirement of men who had hernias with men who did not have hernias although they had some other disabilities. The second sample has 1,904 men. It combines 1,558 men not linked to the Surgeons' Certificates file with 346 hernia patients. We compare retirement of men who had hernias with that of men who were healthy. For men without surgeons' records, we do not have their health information. In addition, since many of them did not apply for pension, and since it is only men in the Pension Records file who were searched for in the 1900 and the 1910 censuses, we do not have demographic information for a substantial number of healthy recruits. Nonetheless, we include all 1,904 men in the second sample by creating a category of missing values for each demographic and health variable. The study, using the first sample, shows the effect of hernias relative to other disabilities on retirement, while using the second sample, it shows the effect of hernias relative to perfect health on retirement.

Three types of sample selection biases may exist. The first type relates to the representation of the UA men over the entire population of white males in the United States of similar birth and socioeconomic backgrounds. The second type of selection bias comes from the screening of potential recruits at enlistment. ${ }^{7}$ The third type of selection bias comes from extracting the variables that are needed for our analysis from each file ${ }^{8}$ of the UA sample and merging the resulting subsamples to create the final data set. Many recruits were dropped during this process because their records were not in all three UA files. By comparing the variable means in the final data set with those in each of the original UA file to detect whether the means have changed significantly after each merge, we conclude that the final data set we use for our analysis represents a random sample of the original UA files. ${ }^{9}$

\subsection{Empirical Framework}

In a standard intertemporal labor-supply model where an individual allocates his resources between consumption $C_{t}$ and leisure $L_{t}$ in each period,

7. Rejections were based on various grounds. For example, the army did not enlist recruits who were in their teens or who were over the age of forty-five. Also, wealthier men who were physically fit could buy substitutes to enlist for them (see Kemp 1990 for a discussion of controversy related to the practice of substitution and the commutation clause in the Enrollment Act and whether average laborers were overrepresented in the Union Army). Furthermore, there are medical disqualifications for military service in the United States. People with chronic diseases, such as abdominal and digestive-apparatus hernia, were exempted from military services in all situations (Baxter 1875, p. li of "Introduction"). Fogel (1993) estimates that 30 percent of the examinees in the UA were rejected for chronic diseases.

8. That is, the Military Records file, the 1900 census file, the 1910 census file, and the Surgeons' Certificates file.

9. We include all the recruits who survive the data-merge into our regressions, even though some of their records are incomplete, by creating dummy variables for missing values. 
the first-order conditions for him to achieve the maximum amount of happiness $U_{t}$ are

$$
\begin{aligned}
& U_{C}\left(C_{t}, L_{t}\right)=\lambda_{t}, \\
& U_{L}\left(C_{t}, L_{t}\right)=\lambda_{t} W_{t},
\end{aligned}
$$

where $\lambda_{t}$ represents the marginal utility of wealth as of time $t ; U_{C}($.$) repre-$ sents the marginal utility with respect to consumption; $U_{L}($.) represents the marginal utility with respect to leisure; and $W_{t}$ represents the wage rate at time $t$.

In this framework, ${ }^{10}$ if wages are exogenous and are not altered by individuals' decisions, declines in current health lower productivity and make working more painful. As a result, individuals work fewer hours. If wages are not exogenous but are dependent on human capital investment, then the more difficult it is to make such an investment, the more likely workers are to leave the work force when suffering health declines. For example, it is more difficult for a machine operator to acquire the skill of a clerk. Therefore, a machine operator is more likely to retire when his health deteriorates to the extent that heavy laboring becomes physically infeasible. Also, for example, it is difficult for older workers to acquire new skills. Therefore, the older workers, when suffering health declines, are more likely to retire, provided that those workers have equal nonwage income. For two workers both suffering from poor health, holding everything else equal, the one who has more nonwage income can more readily afford retirement.

Persistent future health declines affect current labor supply in this framework. Persistent future health declines can be expected to lower future wages and to raise future valuation of leisure. As a result, persistent future health declines raise the marginal valuation of wealth, which will tend to increase current labor supply. This is because individuals want to accumulate more wealth to compensate for fewer hours of work in the future and to avoid working in pain in the future. However, if individuals have been experiencing health declines for a while, they will not be able to increase current labor supply to prepare for the future, even if they want to do so.

Not only can current and future health declines affect the current labor supply, health history also matters. This is because both contemporary and past health conditions determine the future health condition. An individual who has been in poor health for a long time is less likely to recover than an individual who recently suffered a decline in health. In this case, the person who has been in poor health for a longer while will have worse expectations about the future than will the person who recently experienced a negative health shock.

Hernias were considered a persistent, chronic disability during the historical period of investigation, because no reliable treatment was available 
to offer a complete cure. Therefore, once a veteran developed a hernia, he had to cope with it for the rest of his life. We have identified three main factors that determine a worker's decision to exit or remain in the labor force: pain from working as a result of declining health, a wealth level to support fewer hours of work, and high switching costs because of human capital investment. We measure health by hernia screening (yes/no), severity of hernias indicated by hernia ratings, and how long ago a hernia patient had contracted hernias.

We also apply a quadratic function of body mass index (BMI, or weight in kilograms over the square of height in meters) as a control for general health (Costa 1996). We measure income by monthly pension awards granted in the year closest to, but before, 1910. We measure switching costs by the nature of a recruit's occupation in 1900. We assume that switching costs were higher for those individuals engaging in more manually demanding occupations where only physical strength mattered, and lower for those engaging in less manually demanding occupations where training and skills were required. Those with higher switching costs were more likely to retire once they became disabled due to the lack of alternatives.

We next assume that recruits had no hernias prior to enlistment, because hernias disqualified men for military service. Recruits contracted hernias either during the Civil War between 1861 and 1865, or after the war. The military pension for UA recruits started in 1862 . Table 10.5 shows that the first major inflow of recruits who claimed a pension and were examined for conditions that occurred within a decade and a half after the Consolidation Act of 1873. By 1886, 46 percent of the veterans in the Surgeons' Certificates had been examined. There was another major inflow of new pension claimants within three years after the 1890 act. ${ }^{11}$ By 1893,92 percent of the recruits who would eventually have been examined went through their first round of examinations.

We have included about 80 percent of the final hernia patients, when 1900 is chosen as the base year, to study the labor force transition in the next decade. According to the last column of table 10.5, about a third of the recruits who would eventually contract hernias found out by 1890 that they had hernias. Between 1890 and 1900, an additional 44 percent of all eventual hernia patients claimed a pension under this disability. It is not clear whether the large hernia discovery rate between 1890 and 1900 was due to the influx of applicants taking advantage of the $1890 \mathrm{act}$, or to the rise in the risk of hernias as veterans started to reach older ages. ${ }^{12}$ An important as-

11. This is because at the early stage of the development of the UA pension program, a recruit had to prove that the condition under his claim was war related. However, after the 1890 act, this constraint was relaxed, so that a veteran could be entitled to pension with any disability, although a war-related one received a higher rating that was transformed into a higher dollar amount.

12. An average recruit in the Surgeons' Certificates data would be sixty-five by 1900 , and seventy-five by 1910 . 
Table 10.5 Years of First Exams and Years When hernia First Found

\begin{tabular}{|c|c|c|c|c|}
\hline Exam Year & $\begin{array}{l}\text { Number of Recruits } \\
\text { Being Examined } \\
\text { the First Time }\end{array}$ & $\begin{array}{l}\% \text { Recruits } \\
\text { Eventually } \\
\text { Examined }^{\mathrm{a}}\end{array}$ & $\begin{array}{l}\text { Number of Recruits } \\
\text { First Diagnosed } \\
\text { with Hernias }\end{array}$ & $\begin{array}{c}\% \text { Recruits } \\
\text { Eventually Diagnosed } \\
\text { with Hernias }^{\mathrm{a}}\end{array}$ \\
\hline 1861-62 & 5 & 0.1 & 1 & 0 \\
\hline $1863-70$ & 36 & 0.3 & 0 & 0 \\
\hline $1871-73$ & 324 & 3.3 & 44 & 2.0 \\
\hline $1874-86$ & 4,021 & $\begin{array}{c}40.3 \\
(44.0)\end{array}$ & 407 & $\begin{array}{c}19.2 \\
(21.2)\end{array}$ \\
\hline 1887 & 364 & 3.6 & 45 & 2.1 \\
\hline 1888 & 400 & 4.0 & 57 & 2.7 \\
\hline 1889 & 421 & 4.2 & 48 & 2.3 \\
\hline 1890 & 566 & $\begin{array}{c}5.7 \\
(61.5)\end{array}$ & 108 & $\begin{array}{c}5.1 \\
(33.4)\end{array}$ \\
\hline 1891 & 2,205 & 22.1 & 376 & 17.7 \\
\hline 1892 & 709 & 7.1 & 184 & 8.6 \\
\hline 1893 & 137 & $\begin{array}{c}1.4 \\
(92.1)\end{array}$ & 53 & $\begin{array}{c}2.5 \\
(62.2)\end{array}$ \\
\hline 1894-1900 & 521 & $\begin{array}{c}5.2 \\
(97.3)\end{array}$ & 372 & $\begin{array}{c}17.4 \\
(79.6)\end{array}$ \\
\hline $1901-06$ & 235 & 2.4 & 261 & 12.3 \\
\hline $1907-11$ & 13 & 0.1 & 39 & 1.6 \\
\hline $1912-29$ & 19 & 0.2 & 133 & 6.1 \\
\hline Total & 9,976 & 100 & 2,128 & 100 \\
\hline
\end{tabular}

Notes: The Consolidation Act of 1873 established various grades of disability. The 1890 act marked the beginning of a universal disability and old age pension program under which the veteran's disability did not need to be related to military service. Legislation after 1912 consisted mainly of automatic increases in pension ratings for age and service. For a detailed description of the history of pension laws, see Costa (1998, appendix A).

${ }^{\mathrm{a} C}$ Cumulative percent in parentheses.

Table 10.6

OLS Regression of 1910 Hernia Ratings on 1900 Hernia Ratings (369 recruits with nonmissing hernia ratings in both 1900 and 1910)

\begin{tabular}{lcc}
\hline & Coefficient Estimates & $T$-statistics \\
\hline Intercept & $0.1772^{* * *}$ & 7.81 \\
1900 hernia ratings & $0.6132^{* * *}$ & 11.69 \\
Dependent variable (1910 Hernia Ratings) mean & 0.43 & \\
Independent variable (1900 Hernia Ratings) mean & 0.39 & \\
Adjusted $R^{2}$ & 0.2686 & \\
\hline
\end{tabular}

***Significant at the 1 percent level.

pect for our study is that we have captured most of the hernia patients in our sample.

We argue that past (1900) and contemporaneous (1910) health status contributes to labor participation decisions. Table 10.6 presents the ordinary least squares (OLS) regression of hernia ratings in 1910 on a constant 
Occupations Coded Using the 1950 Census of Population Index

\begin{tabular}{llc}
\hline & \multicolumn{1}{c}{ Classification I } & \multicolumn{1}{c}{ Classification II } \\
\hline (L) Less manually demanding & $\begin{array}{c}\text { Professional, technical, and } \\
\text { kindred workers } \\
\text { Managers, officials, and }\end{array}$ & $\begin{array}{c}\text { Classification I, plus farmers } \\
\text { and farm managers }\end{array}$ \\
& proprietors & \\
& Clerical and kindred workers & \\
& Sales workers & \\
& Farmers and farm managers & Classification I, excluding \\
& Craftsmen, foremen, and & farmers and farm managers \\
& kindred workers & \\
& Operatives and kindred workers & \\
& Service workers & \\
& Farm laborers and foremen & \\
& Laborers, except farm and mine & \\
& & \\
& &
\end{tabular}

aFollowing Lee (1998), we define retirees as those whose occupation was recorded as "retired," blank, "invalid or sick or disabled," "inmate or prisoner," "landlord," or "capitalist or gentlemen." To distinguish retirees from the unemployed, we define the latter as those whose occupation was recorded as "unemployed or without occupation."

term and on hernia ratings in 1900. If past health status possesses large predictive power over present health status, we would observe the adjusted $R$ squared to be close to 1 , and the slope coefficient to be also close to 1 and to be statistically significant. Table 10.6 shows that past health partially predicts present health by explaining 27 percent of the variation in present health $\left(R^{2}=0.2686\right)$. The intercept is 0.18 , or about 45 percent of past hernia ratings $(0.1772 / 0.39)$. The coefficient estimate is 0.61 , which means that, on average, 61 percent of ratings in 1900 would contribute to our inference of ratings in 1910. Since the 1910 ratings contain new health information that is not captured by the 1900 ratings, we will use the 1900 ratings and the 1910 ratings to measure health.

If hernias were physically debilitating, we would expect workers in more manually demanding occupations to have higher retirement probabilities. Occupations are coded using the index in the 1950 census of population. We assign occupations into three categories: $:^{13}$ less manually demanding, more manually demanding, and retired (see table 10.7). Out of 3,406 recruits in the 1900 labor force, 1,478 recruits were farmers and farm managers (43.39 percent). Obviously, one of the responsibilities of farmers and farm managers was management of farms, which probably required some skills and training. Also, many of them were owners of farms, so that they belonged

13. There are two possibilities as to why a recruit who was linked to a census failed to have an occupational record: (a) The recruit had a job but did not report it, or (b) the recruit was unemployed and did not report his usual occupation. 


\begin{tabular}{cccc}
\hline & \multicolumn{3}{c}{1910 Category } \\
\cline { 2 - 4 } 1900 Category & $\begin{array}{c}\text { Less Manually } \\
\text { Demanding }\end{array}$ & $\begin{array}{c}\text { More Manually } \\
\text { Demanding }\end{array}$ & Retired \\
\hline A. Farmers and farm managers classified & as more manually & demanding occupation \\
Less manually demanding (718 veterans) & 54.74 & 22.42 & 22.84 \\
More manually demanding (2,688 veterans) & 5.25 & 70.16 & 24.59 \\
B. Farmers and farm managers classified as less manually & demanding occupation \\
Less manually demanding (2,196 veterans) & 61.48 & 12.84 & 25.68 \\
More manually demanding (1,210 veterans) & 16.53 & 61.90 & 21.57 \\
\hline
\end{tabular}

to a wealthier social class than farm laborers who only supplied physical labor for subsistence-level compensation. Because farmers and farm managers accounted for a high percentage of the labor force, and because their tasks included fieldwork (which was physically intensive) and general management (which was skill intensive), we group them using two classifications. In the first classification, farmers and farm managers are identified as more manually demanding occupations. In the second classification, they are identified as less manually demanding occupations.

Table 10.8 displays the occupational transition between 1900 and 1910 for those veterans who were in the labor force in $1900 .{ }^{14}$ There were 3,406 veterans linked to both the 1900 and the 1910 census files. Panel A shows the transition under Classification I, where farmers and farm managers are classified as more manually demanding occupations. The more manually demanding category has a higher occupational persistence because 70 percent remained in the same category ten years later. In comparison, about half of the veterans who engaged in less manually demanding occupations in 1900 remained in the same category.

A fair proportion of veterans retired from their 1900 occupations in 1910. The percentage is slightly higher among more manually demanding occupations in $1900 .{ }^{15}$ Few veterans in the more manually demanding category

14. Some of those veterans who were either retired or unemployed in 1900 could have returned to labor force in 1910. Lee (1998) detected persistence in the long-tern unemployment among older males. He found that for those men aged fifty or older in 1900, being unemployed in 1900 greatly increased the chances of retirement within the next ten years.

15. Costa found that, with the inclusion of retirement as a professional category, workers within the most physically demanding occupational categories (i.e., laborers and farmers) were the men most likely to retire (Costa 1998, 90, table 5.8). She used an earlier version of the 1900 and 1910 census data, which did not contain as many recruits as the current version. Margo (1993) used data from the 1900 census to study the proper labor force classification of older male Americans experiencing six months or more of unemployment (the long-term unemployed). He found that long-term unemployment was more prevalent among unskilled laborers and the building trades. The probability of long-term unemployment also rose with age, after controlling for occupation. Finally, the older an individual was on entering the state of 
switched to the less manually demanding category. In contrast, occupational changes occurred four times as frequently for those in the less manually demanding category. This is consistent with the human capital argument that switching-costs were higher for those individuals engaging in occupations that required less human capital investment, and lower for those engaging in occupations where education and training were important.

Panel B shows the transition under the second classification, where farmers and farm managers are classified as less manually demanding occupations. Occupational persistence is the same between less manually demanding jobs (61.48 percent) and more manually demanding jobs $(61.90$ percent). Comparing panel $\mathrm{A}$ with panel $\mathrm{B}$, we conclude that farmers and farm managers tended to remain in the same occupational category between 1900 and 1910. Including them in the less manually demanding group increases the persistence in that group from 54.7 percent to 61.48 percent. We also infer that some farm laborers and foremen might have acquired the farmland and become farmers and farm managers during the ten-year period. This is because the labor market mobility in the more manually demanding jobs increases from 5.25 percent in panel A, where farm owners and farm laborers are classified as being in the same occupational group, to 16.53 percent in $\mathrm{B}$, where they are classified as being in different occupational groups and where moves between those groups are considered switching.

Classifications I and II represent a very crude measure of the extent of labor intensiveness of different occupations. Within the manually demanding occupational category, there can be a large variation in the degree of physical exertion required. Table 10.8 indicates that men in more manually demanding jobs in 1900 are unlikely to switch to less manually demanding jobs in 1910. However, for those who remained in the more manually demanding category in 1910, there could be switches from very physically intensive occupations to much less physically intensive occupations. For example, a factory worker might become a janitor if he contracted hernias and desired a less physically demanding occupation.

We extract a subsample of men whose occupations were classified as more manually demanding and code each occupation according to how physically intensive each occupation is: not much, somewhat, or very. Table 10.9 lists occupations under each group of physical intensity. Notice that in panel A of table 10.9, farm foremen and farm laborers are grouped under "very physically intensive," whereas farm owners and tenants are grouped under "not much physically intensive." We distinguish between physical in-

long-term unemployment, the greater the likelihood that he would leave the labor force in a short period of time. Our result that retirement is slightly higher among more manually demanding occupations circa 1900 is consistent with both Costa's and Margo's findings. 
Table 10.9

Degree of Intensity of Manually Demanding Occupations, Including

Farmers and Farm Managers

Degree of intensity

Occupation

\section{A. Degree of physical intensity}

Not much physically intensive

Attendants, hospital and other institution

Attendants, professional and personal service

Barbers, beauticians, and manicurists

Compositors and typesetters

Conductor, bus and street railway

Dressmakers and seamstresses except factory

Farmers (owners and tenants)

Jewelers, watchmakers, goldsmiths, and silversmiths

Marshals and constables

Milliners

Policemen and detectives

Service workers, except private household

Sheriffs and bailiffs

Tailors and tailoresses

Taxicab drivers and chauffeurs

Somewhat physically intensive

Watchmen (crossing) and bridge tenders

Bakers

Bartenders

Boarding and lodging-house keepers

Bookbinders

Charwomen and cleaners

Cooks, except private household

Decorators and window dressers

Deliverymen and routemen

Electricians

Elevator operators

Farm managers

Furriers

Guards, watchmen, and doorkeepers

Housekeepers and stewards, except private household

Housekeepers, private household

Inspectors

Inspectors, scalers, and graders, $\log$ and lumber

Janitors and sextons

Locomotive engineers

Meat cutters, except slaughter and packing house

Mechanics and repairmen

Mechanics and repairmen, automobile

Mechanics and repairmen, railroad and car shop

Opticians and lends grinders and polishers

Painters, except construction or maintenance

Paperhangers

Photoengravers and lithographers

Piano and organ tuners and repairmen

Plasterers

Private household workers

Shoemakers and shoe repairers, except factory 


\begin{tabular}{|c|c|}
\hline Very physically intensive & $\begin{array}{l}\text { Stationary engineers } \\
\text { Switchmen, railroad } \\
\text { Teamsters } \\
\text { Truck and tractor drivers } \\
\text { Waiters and waitresses } \\
\text { Weavers, textile } \\
\text { Apprentice bricklayers and masons } \\
\text { Apprentices, metalworking trades } \\
\text { Apprentices, other specified trades } \\
\text { Blacksmiths } \\
\text { Boatmen, canalmen, and lock keepers } \\
\text { Boilermakers } \\
\text { Brakemen, railroad } \\
\text { Brickmasons, stonemasons, and tile setters } \\
\text { Cabinetmakers } \\
\text { Carpenters } \\
\text { Craftsmen and kindred workers } \\
\text { Dyers } \\
\text { Engravers, except photoengravers } \\
\text { Excavating, grading, and road machinery operators } \\
\text { Farm foremen } \\
\text { Farm laborers, wage workers } \\
\text { Filers, grinders, and polishers, metal } \\
\text { Firemen, fire protection } \\
\text { Fishermen and oystermen } \\
\text { Foremen } \\
\text { Fruit, nut, and vegetable graders, and packers, except } \\
\text { factory } \\
\text { Furnacemen, smeltermen, and pourers } \\
\text { Gardeners, except farm, and groundskeepers } \\
\text { Glaziers } \\
\text { Heat treaters, annealers, temperers } \\
\text { Laborers } \\
\text { Laundry and dry-cleaning operatives } \\
\text { Locomotive firemen } \\
\text { Longshoremen and stevedores } \\
\text { Lumbermen, raftsmen, and woodchoppers } \\
\text { Machinists } \\
\text { Millers, grain, flour, feed, etc. } \\
\text { Millwrights } \\
\text { Mine operatives and laborers } \\
\text { Molders, metal } \\
\text { Motormen, mine, factory, logging camp, etc. } \\
\text { Operative and kindred workers } \\
\text { Painters, construction and maintenance } \\
\text { Plumbers and pipe fitters } \\
\text { (collers and roll hands, metal }\end{array}$ \\
\hline
\end{tabular}




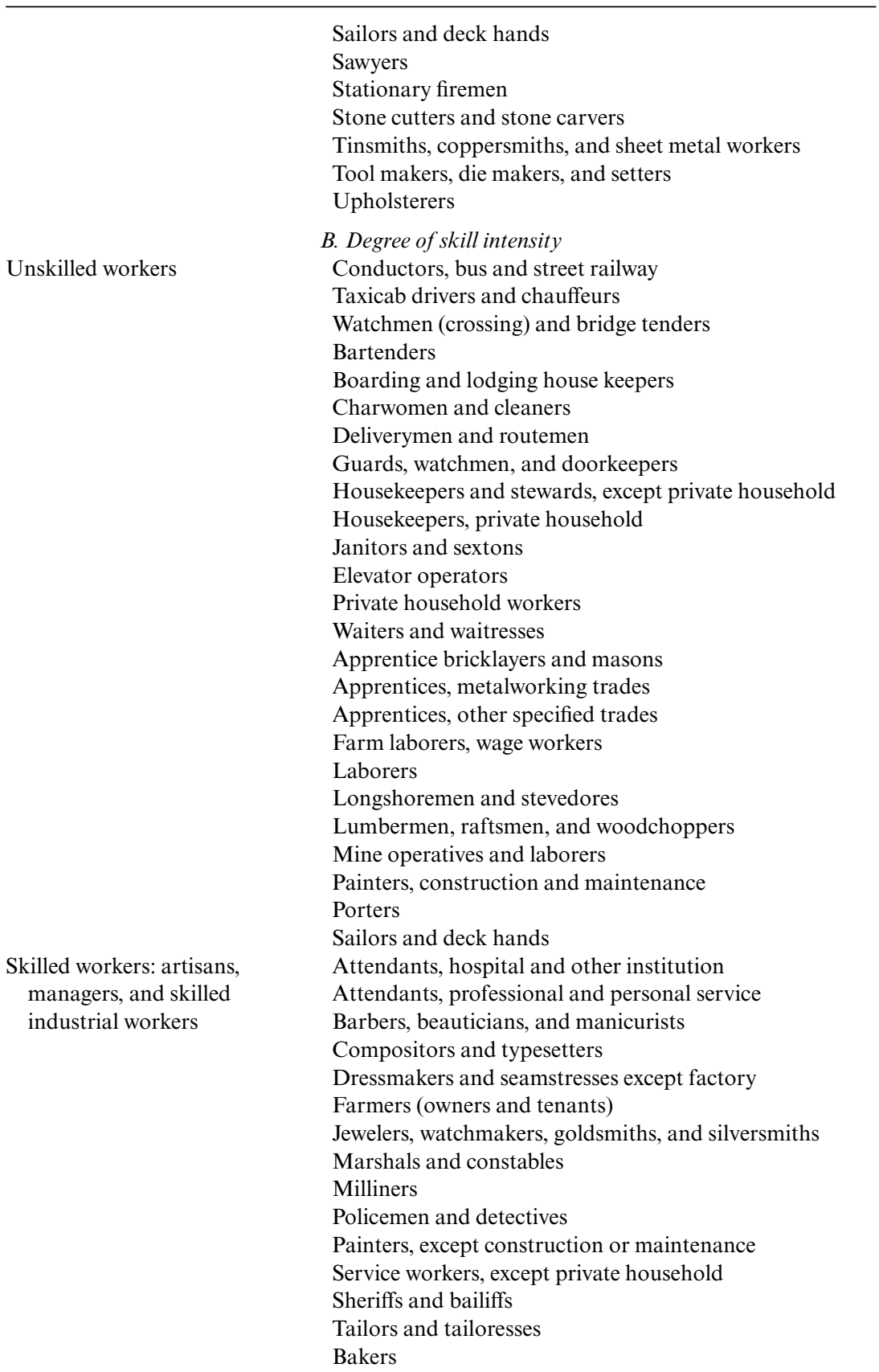


Bookbinders

Cooks, except private household

Decorators and window dressers

Electricians

Farm managers

Furriers

Inspectors

Inspectors, scalers, and graders, log and lumber

Locomotive engineers

Meat cutters, except slaughter and packing house

Mechanics and repairmen

Mechanics and repairmen, automobile

Mechanics and repairmen, railroad and car shop

Opticians and lens grinders and polishers

Paperhangers

Photoengravers and lithographers

Piano and organ tuners and repairmen

Plasterers

Shoemakers and shoe repairers, except factory

Stationary engineers

Switchmen, railroad

Teamsters

Truck and tractor drivers

Weavers, textile

Blacksmiths

Boatmen, canalmen, and lock keepers

Boilermakers

Brakemen, railroad

Brickmasons, stonemasons, and tile setters

Cabinetmakers

Carpenters

Craftsmen and kindred workers

Dyers

Engravers, except photoengravers

Excavating, grading, and road machinery operators

Farm foremen

Filers, grinders, and polishers, metal

Firemen, fire protection

Fishermen and oystermen

Foremen

Fruit, nut, and vegetable graders, and packers, except factory

Furnacemen, smeltermen, and pourers

Gardeners, except farm, and groundskeepers

Glaziers

Heat treaters, annealers, temperers

Laundry and dry-cleaning operatives

Locomotive firemen

(continued) 
Table 10.9 (continued)

\begin{tabular}{ll}
\hline Degree of intensity & \multicolumn{1}{c}{ Occupation } \\
\hline Machinists \\
Millers, grain, flour, feed, etc. \\
Millwrights \\
Molders, metal \\
Motormen, mine, factory, logging camp, etc. \\
Operative and kindred workers \\
Plumbers and pipe fitters \\
Rollers and roll hands, metal \\
Sawyers \\
Stationary firemen \\
Stone cutters and stone carvers \\
Tinsmiths, coppersmiths, and sheet metal workers \\
Tool makers, die makers, and setters \\
Upholsterers \\
\hline
\end{tabular}

tensity and skill intensity: The former measures the amount of effort exerted to perform manual labor, whereas the latter measures the level of human capital requirement. Having contracted hernias might stop an individual from remaining in occupations with high physical intensity, but might not hinder him in remaining in occupations with high skill intensity.

Even within the manually demanding occupational category, we observe a large skill variance in every job. For example, a bookbinder could not have taken on the tasks of a jeweler, or a carpenter could not have replaced a locomotive engineer. Ransom and Sutch (1986) argued that older men could extend their work lives by switching from skilled and semiskilled jobs to unskilled jobs. They call this phenomenon "downward occupational mobility." An implication of their finding is that workers in more-skilled and semiskilled jobs are less likely to retire than workers in unskilled jobs because of the option to switch. Panel B of table 10.9 reclassifies jobs in the more manually demanding occupations according to skill intensity, using the definition in Ransom and Sutch. Jobs considered very physically demanding in panel A could also be skill intensive in panel B. Some examples are machinists, locomotive firemen, brickmasons, and dyers.

Table 10.10, panel A, presents occupational transitions for veterans in more manually demanding occupations in 1900 when they are classified according to physical intensity. There are large numbers of farm owners and tenants, because when they are excluded from 1900 manually demanding occupations, the number of veterans in not much physically intensive jobs drop from 1,521 in panel A to 43 in panel B. In panel A, a negative relationship exists between the rate of retirement and the degree of labor intensiveness. Farm owners and tenants, who dominate this group, had a higher retirement rate. Veterans in more physically intensive occupations tended to stick to the same group (57.09 percent) and tended to have lower retire- 


\begin{tabular}{|c|c|c|c|c|c|}
\hline \multirow{5}{*}{$\begin{array}{l}\text { Number of } \\
\text { Veterans in } \\
1900 \text { Category }\end{array}$} & \multicolumn{5}{|c|}{1910 Category } \\
\hline & \multirow{4}{*}{$\begin{array}{c}\text { Less } \\
\text { Manually } \\
\text { Demanding }\end{array}$} & \multicolumn{3}{|c|}{ More Manually Demanding } & \multirow[b]{4}{*}{ Retired } \\
\hline & & Not Much & Somewhat & Very & \\
\hline & & Physically & Physically & Physically & \\
\hline & & Intensive & Intensive & Intensive & \\
\hline \multicolumn{6}{|c|}{ A. Farmers and farm managers classified as more manually demanding occupation, by physical intensity } \\
\hline 1,521 in not much physically intensive & 3.22 & 58.57 & 1.77 & 9.47 & 26.96 \\
\hline 175 in somewhat physically intensive & 10.86 & 8.00 & 34.86 & 22.28 & 24.00 \\
\hline 992 in very physically intensive & 7.36 & 9.82 & 4.66 & 57.09 & 21.07 \\
\hline \multicolumn{6}{|c|}{ B. Farmers and farm managers classified as less manually demanding occupation, by physical intensity } \\
\hline 43 in not much physically intensive & 18.60 & 25.58 & 9.30 & 23.26 & 23.26 \\
\hline 175 in somewhat physically intensive & 18.29 & 0.57 & 34.86 & 22.28 & 24.00 \\
\hline \multirow[t]{4}{*}{992 in very physically intensive } & 16.13 & 1.01 & 4.66 & 57.13 & 21.07 \\
\hline & & \multicolumn{4}{|c|}{ More Manually Demanding } \\
\hline & & Less & & & \\
\hline & & $\begin{array}{l}\text { Manually } \\
\text { Demanding }\end{array}$ & Unskilled & Skilled & Retired \\
\hline \multicolumn{6}{|c|}{ C. Farmers and farm managers classified as more manually demanding occupation, by skill intensity } \\
\hline 522 unskilled veterans & & 6.90 & 42.08 & 25.74 & 25.29 \\
\hline 2,166 skilled veterans & & 4.85 & 7.82 & 62.91 & 24.42 \\
\hline \multicolumn{6}{|c|}{ D. Farmers and farm managers classified as less manually demanding occupation, by skill intensity } \\
\hline 522 unskilled veterans & & 18.97 & 42.10 & 13.65 & 25.29 \\
\hline 688 skilled veterans & & 14.68 & 9.78 & 56.79 & 18.75 \\
\hline
\end{tabular}

ment probability (21.07 percent). It is more difficult for men in very physically intensive jobs to switch to other jobs within the manually demanding category due to the lack of job-specific knowledge. It is also more difficult for them to retire since the average income for this group is low. Table panels $\mathrm{C}$ and $\mathrm{D}$ of table 10.10 present occupational transitions for veterans in more manually demanding occupations in 1900 when they are classified according to skill intensity. As with panels A and B, the difference between panels $\mathrm{C}$ and $\mathrm{D}$ is that farm owners and managers who are considered skilled workers are included in the former but excluded in the latter. Retirement among the skilled was lower, although there was not much trickling down from skilled to unskilled occupations for those remaining in the labor force in more manually demanding occupations, because only 7.82 percent of the skilled veterans in 1900 switched to unskilled, manually demanding occupations in 1910, and that percentage was 9.78 percent in panel D.

Apart from switching costs, existing income is another crucial parameter in labor market decisions. The census file records three indicator variables that represent the wealth holdings of a household that a veteran belonged 
to: whether the household had a farm versus a house, whether the household owned the property or rented it, and whether there was a mortgage left to be paid. We decided not to incorporate those indicators because the value of a piece of land or property could be dramatically different from one area to another. It would be inappropriate to assume that two households were equally wealthy based on the information that they both owned property. The census file does not have other wealth data except in indicator forms. We decided to use the monthly amount of pension a veteran received from the Pension Bureau as an income measure. ${ }^{16}$ This is because the average annual pension was a substantial portion of the average annual per capita national income. Pension awards, therefore, could have a significant impact on a veteran's incentive to retire.

Given that a recruit was in the labor force in 1900, define the probabilities of two outcomes as

$$
\begin{gathered}
p_{r}=\operatorname{prob}(Y=1 \mid L \text { or } M)=\operatorname{prob}(\text { retirement in } 1910 \mid L \text { or } M) \\
1-p_{r}=\operatorname{prob}(Y=0 \mid L \text { or } M) \\
=\operatorname{prob}(\text { remained in labor force in } 1910 \mid L \text { or } M)
\end{gathered}
$$

We assume that recruit $i$ 's probability of each outcome can be approximated as a logistic function of health, pension income, switching costs, and other unobserved factors, $\varepsilon_{i}$, controlling for $k$-dimensional demographic characteristics in 1900, $x_{k i}$. Omit the recruit index $i$ to simplify notation. We fit the logistic model

$$
\operatorname{logit}\left(p_{r}\right)=\log \left(\frac{p_{r}}{1-p_{r}}\right)=\alpha_{1}+\beta^{\prime} x
$$

Equation (4) can be reformulized as

$$
p_{r}=\frac{e^{\alpha}+\beta_{1} x}{1+e^{\alpha_{1}+\beta^{\prime} x}}
$$

The slope of the logistic regression with respect to any explanatory variable $x_{k}$ is

$$
\frac{\partial p_{r}}{\partial x_{k}}=p_{r}\left(1-p_{r}\right) \beta_{k} .
$$

Demographic characteristics $x_{k i}$ include birth cohorts, nativity, residence, literacy, and household features. Original birthplaces were reported by recruits at enlistment and were stored in the Military Service Records file. At enlistment, 71 percent of the recruits were native-born. By the time of the pension, 90 percent of the pensioned veterans were native-born.

16. In an earlier version of the paper, we experimented with the household wealth indicators and found that none of them possess significant explanatory power over retirement. There are two explanations for this result: Nonliquid asset holdings do not have any impact on the labor participation of UA veterans, or zero-one property dummies are not accurate wealth measures. 
Compared to the proportion of native-born veterans at enlistment, the proportion of native-born veterans who later entered the pension program was higher. Perhaps immigrants were at a disadvantage when they applied for pensions, because it was more difficult for them to provide the Pension $\mathrm{Bu}$ reau with proof of identification and evidence of service.

Degree of urbanization of the 1900 residential county is also of interest to us because it approximates the residential population density. ${ }^{17}$ Employment opportunities differ between urban and rural areas. Residents in urban areas were more likely to participate in the labor force and to engage in certain types of occupations. To a limited extent, literacy measures the intellectual capacity of a veteran. A veteran who could not read or write had limited employment opportunities. We realize, however, that literacy is a very crude proxy of basic education. ${ }^{18}$ Finally, a veteran's marital status and head-of-household status could affect the resource allocation within the household, which could in turn affect labor participation.

\subsection{Results}

Table 10.11 compares health, pension income, household, and demographic characteristics of the 1900 samples of less manually demanding professions, more manually demanding professions, and recruits who were in the labor force overall. Farmers and farm managers are classified as more manually demanding occupations. The three samples are similar in terms of health and pension income. Because monthly pension award was based on the health condition of veterans, comparable means on health and pensionincome variables indicate that pension was granted regardless of occupational classification. There is a slightly higher percentage of native-born and literate recruits in the less manually demanding jobs, because citizens enjoyed a social advantage over immigrants in the labor market, and because more educated individuals were better prepared to take on professional positions. ${ }^{19}$

Cohort and regional compositions in table 10.11 are notably different between the less versus the more manually demanding occupation samples. The proportion of veterans who were born between 1812 and 1839, or who were over the age of sixty by 1900 , is higher in the more manually demanding category. This observation is rather counterintuitive, considering that physical strength, which was needed in this occupational category, normally declines during the aging process. But after we study the cohort composition in table 10.12, where farmers and farm managers are classified as less manually demanding occupations instead, we discover that the higher

17. A county is urban if it contains at least one city with a population of 25,000 or over. There are 165 urban counties in the 1900 census.

18. If a veteran could sign his name, he would be considered literate.

19. See Blanck and Song (2001) for a comparison of pension application experience between native and foreign-born recruits. 


\begin{tabular}{|c|c|c|c|}
\hline & $\begin{array}{c}370 \text { Veterans in } \\
\text { Less Manually } \\
\text { Demanding } \\
\text { Professions }\end{array}$ & $\begin{array}{l}\text { 1,426 Veterans in } \\
\text { More Manually } \\
\text { Demanding } \\
\text { Professions }\end{array}$ & $\begin{array}{l}\text { Overall (both more } \\
\text { and less manually } \\
\text { demanding } \\
\text { professions) }\end{array}$ \\
\hline 1900 in labor force, 1910 retired & 24.32 & 25.39 & 25.17 \\
\hline Had hernias by 1900 & 13.51 & 14.24 & 14.09 \\
\hline Rated 0.0000 & 0.00 & 0.28 & 0.22 \\
\hline Rated $0.1111-0.1667$ & 0.81 & 0.98 & 0.95 \\
\hline Rated 0.2222 & 1.89 & 1.75 & 1.78 \\
\hline Rated $0.2500-0.5000$ & 4.59 & 4.00 & 4.12 \\
\hline Rated $0.5556-0.6250$ & 1.62 & 2.24 & 2.12 \\
\hline Rated $0.6667-1.0000$ & 0.81 & 1.05 & 1.00 \\
\hline Rating missing & 3.78 & 3.93 & 3.90 \\
\hline Had hernias by 1910 & 19.19 & 18.72 & 18.82 \\
\hline Rated 0.0000 & 1.08 & 0.07 & 0.28 \\
\hline Rated $0.1111-0.1667$ & 0.00 & 0.63 & 0.50 \\
\hline Rated 0.2222 & 0.81 & 0.98 & 0.95 \\
\hline Rated $0.2500-0.5000$ & 1.62 & 1.47 & 1.50 \\
\hline Rated $0.5556-0.6250$ & 0.81 & 1.96 & 1.73 \\
\hline Rated $0.6667-1.0000$ & 0.54 & 0.91 & 0.84 \\
\hline Rating missing & 14.32 & 12.69 & 13.03 \\
\hline Years having contracted hernias by 1900 & 1.59 & 1.59 & 1.59 \\
\hline BMI at first exam & 23.32 & 22.87 & 22.97 \\
\hline Square of BMI at first exam & 553.13 & 530.00 & 534.77 \\
\hline $1812-34$ & 5.41 & 9.05 & 8.30 \\
\hline $1835-39$ & 15.68 & 20.62 & 19.60 \\
\hline $1840-44$ & 50.81 & 46.21 & 47.16 \\
\hline $1845-51$ & 22.16 & 20.69 & 20.99 \\
\hline Birth year missing & 5.95 & 3.44 & 3.95 \\
\hline 1900 head of household & 91.08 & 94.46 & 93.76 \\
\hline 1900 household relationship missing & 2.70 & 1.26 & 1.56 \\
\hline \multicolumn{4}{|l|}{1900 number of residents in } \\
\hline the household & 3.02 & 3.28 & 3.23 \\
\hline 1900 married & 88.11 & 89.20 & 88.98 \\
\hline Native-born & 90.27 & 87.66 & 88.20 \\
\hline Able to read & 96.49 & 94.46 & 94.88 \\
\hline Literacy unknown & 3.24 & 1.54 & 1.89 \\
\hline \multicolumn{4}{|l|}{1900 residence } \\
\hline Northeast region & 30.27 & 40.60 & 38.47 \\
\hline South region & 2.70 & 3.72 & 3.51 \\
\hline West region & 5.14 & 3.02 & 3.45 \\
\hline Midwest region & 59.46 & 51.47 & 53.12 \\
\hline Unknown & 2.43 & 1.19 & 1.45 \\
\hline Urban county & 32.43 & 21.32 & 23.61 \\
\hline \multicolumn{4}{|l|}{ Monthly pension aware before and closest } \\
\hline to 1910 & $\$ 14.92$ & $\$ 14.70$ & $\$ 14.75$ \\
\hline
\end{tabular}

Notes: Dummies in percentages. Sample I consists of men linked to surgeons' data. In Classification I, farmers and farm managers are classified as more manually demanding occupations. If a recruit did not have hernias by 1900 , he had zero year of contracting hernias. If he was diagnosed of hernias in 1900, we assume that he had one year of contracting hernias. In general, for a hernia patient, years of contracting hernias are equal to the difference between 1901 and the exam year during which he was diagnosed of hernias for the first time. For the entire sample of 1,812 recruits, the average number of years recruits had hernias was 1.59 years. The average was small because many recruits who did not have hernias were assigned a value of zero for the length of period contracting hernias. The average length of period contracting hernias for 253 hernia patients (not shown in this table) is 11.32 years. 


\begin{tabular}{|c|c|c|c|}
\hline & $\begin{array}{l}\text { 1,125 Veterans in } \\
\text { Less Manually } \\
\text { Demanding } \\
\text { Professions } \\
\text { in } 1900\end{array}$ & $\begin{array}{l}671 \text { Veterans in } \\
\text { More Manually } \\
\text { Demanding } \\
\text { Professions } \\
\text { in } 1900\end{array}$ & $\begin{array}{l}\text { Overall (both more } \\
\text { and less manually } \\
\text { demanding } \\
\text { professions } \\
\text { in 1900) }\end{array}$ \\
\hline 1900 in labor force, 1910 retired & 27.73 & 20.86 & 25.17 \\
\hline Had hernias by 1900 & 13.33 & 15.35 & 14.09 \\
\hline Rated 0.0000 & 0.09 & 0.45 & 0.22 \\
\hline Rated $0.1111-0.1667$ & 0.89 & 1.04 & 0.95 \\
\hline Rated 0.2222 & 1.96 & 1.49 & 1.78 \\
\hline Rated $0.2500-0.5000$ & 4.53 & 3.43 & 4.12 \\
\hline Rated $0.5556-0.6250$ & 1.87 & 2.53 & 2.12 \\
\hline Rated $0.6667-1.0000$ & 0.98 & 1.04 & 1.00 \\
\hline Rating missing & 3.02 & 5.37 & 3.90 \\
\hline Had hernias by 1910 & 17.42 & 21.16 & 18.82 \\
\hline Rated 0.0000 & 0.44 & 0 & 0.28 \\
\hline Rated $0.1111-0.1667$ & 0.36 & 0.75 & 0.50 \\
\hline Rated 0.2222 & 1.24 & 0.45 & 0.95 \\
\hline Rated $0.2500-0.5000$ & 1.33 & 1.79 & 1.50 \\
\hline Rated $0.5556-0.6250$ & 1.42 & 2.24 & 1.73 \\
\hline Rated $0.6667-1.0000$ & 0.80 & 0.89 & 0.84 \\
\hline Rating missing & 11.82 & 15.05 & 13.03 \\
\hline Years having contracted hernias by 1900 & 1.46 & 1.83 & 1.59 \\
\hline BMI at first exam & 23.03 & 22.85 & 22.97 \\
\hline Square of BMI at first exam & 538.08 & 529.19 & 534.77 \\
\hline \multicolumn{4}{|l|}{ Birth year } \\
\hline $1812-34$ & 8.62 & 7.75 & 8.30 \\
\hline $1835-39$ & 19.91 & 19.08 & 19.60 \\
\hline $1840-44$ & 47.38 & 46.80 & 47.16 \\
\hline $1845-51$ & 20.36 & 22.06 & 20.99 \\
\hline Birth year missing & 3.73 & 4.32 & 3.95 \\
\hline 1900 head of household & 95.64 & 90.61 & 93.76 \\
\hline 1900 household relationship missing & 1.42 & 1.79 & 1.56 \\
\hline \multicolumn{4}{|l|}{1900 number of residents in the } \\
\hline household & 3.26 & 3.17 & 3.23 \\
\hline 1900 married & 89.78 & 87.63 & 88.98 \\
\hline Native-born & 89.87 & 85.39 & 88.20 \\
\hline Able to read & 95.47 & 93.89 & 94.88 \\
\hline Literacy unknown & 1.96 & 1.79 & 1.89 \\
\hline \multicolumn{4}{|l|}{1900 residence } \\
\hline Northeast region & 30.31 & 52.16 & 38.47 \\
\hline South region & 4.18 & 2.38 & 3.51 \\
\hline West region & 3.29 & 3.73 & 3.45 \\
\hline Midwest region & 60.80 & 40.24 & 53.12 \\
\hline Unknown & 1.42 & 1.49 & 1.45 \\
\hline Urban county & 17.51 & 33.83 & 23.61 \\
\hline \multicolumn{4}{|l|}{ Monthly pension aware before and closest } \\
\hline to 1910 & $\$ 14.90$ & $\$ 14.49$ & $\$ 14.75$ \\
\hline
\end{tabular}

Notes: Dummies in percent. Sample I consists of men linked to surgeons' data. In Classification II, farmers and farm managers are classified as less manually demanding occupations. If a recruit did not have hernias by 1900, he had zero year of contracting hernias. If he was diagnosed of hernias in 1900, we assume that he had one year of contracting hernias. In general, for a hernia patient, years of contracting hernias are equal to the difference between 1901 and the exam year during which he was diagnosed of hernias for the first time. For the entire sample of 1,812 recruits, the average number of years recruits had hernias was 1.59 years. The average was small because many recruits who did not have hernias were assigned a value of zero for the length of period contracting hernias. The average length of period contracting hernias for 253 hernia patients (not shown in this table) is 11.32 years. 
percentage of the elderly in table 10.11 is due to the fact that farmers and farm managers are classified as more manually demanding occupations, and that they remained as caretakers of their farmland even after the normal retirement age. In fact, table 10.12 shows that the age composition is similar between the two occupational groups. The proportion of older veterans is slightly higher in the less manually demanding occupations, as one usually expects.

As demonstrated in both table 10.11 and table 10.12, there is a close link between occupation and region. A higher proportion of veterans in more manually demanding jobs resided in the industrialized Northeast, where operatives, kindred workers, service workers, and other nonfarm workers were in demand. In both occupational categories, a substantial number of recruits resided in the Midwest region. The proportion of Midwestern residents who were in the more manually demanding occupational group is higher in table 10.11 (51.47 percent) than in table 10.12 (40.24 percent), because farmers and farm managers who resided primarily in the Midwest are classified as the more manually demanding group in table 10.11, whereas they are not in table 10.12. We also notice that farmers and farm managers were not urban dwellers. This is because the occupational group to which they belong has a smaller percentage of individuals living in urban areas.

The effect of hernias on labor force transitions of veterans who were linked to surgeons' data is summarized in table 10.13 and table 10.14. Table 10.13 corresponds to the classification that includes farmers and farm managers in the more manually demanding group, and table 10.14 corresponds to the classification that excludes them from that group. In each table, the probability of retirement is explained by health, pension income, jobswitching cost, cohort, nativity, literacy, and regional factors. We investigate four models. The first model treats health status as a combination of a general measure, BMI, and a specific measure, hernia screen. The second model replaces the zero-one hernia screen with a continuous hernia-ratings variable. The third model adds the length of period contracting hernias into the second model. Because the debilitating potential of hernias is at the core of our study, we want to test the robustness of our results by experimenting with various specifications in those three models. Finally, for the fourth model we add to the third model the interactions of the 1900 less manually demanding occupation dummy variable with regional dummies and with the hernia screen, and then the interaction of the hernia screen with pension income. Regional interaction terms act as controls for occupational differences resulting from labor specialization in certain geographical locations. Interactions with the hernia screen present an answer to the question of whether hernias affected individuals differently in less versus more manually demanding occupations, and whether wealthier hernia patients were more likely to retire.

Table 10.13 shows that hernias had a weak influence on retirement. In the 


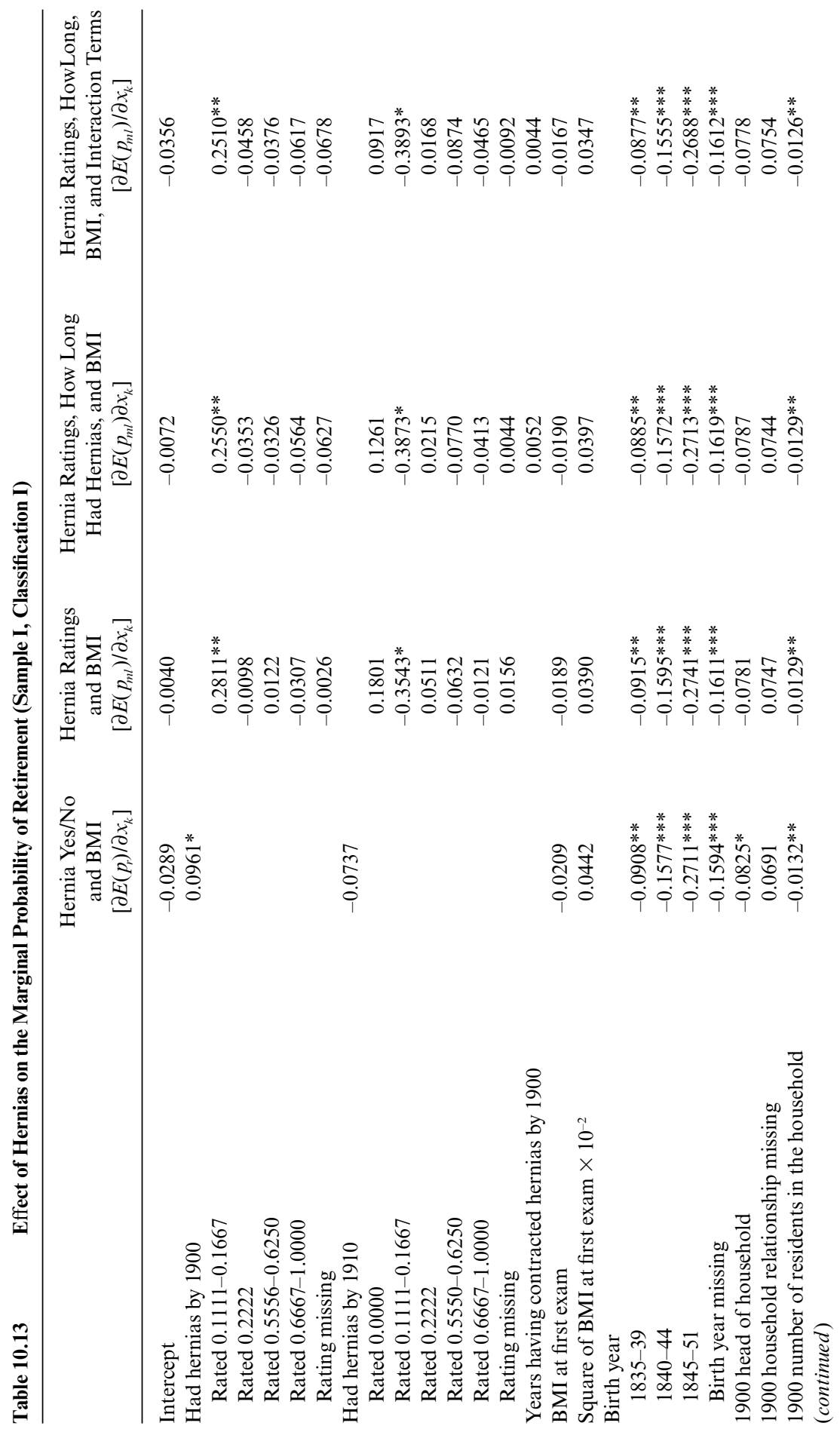




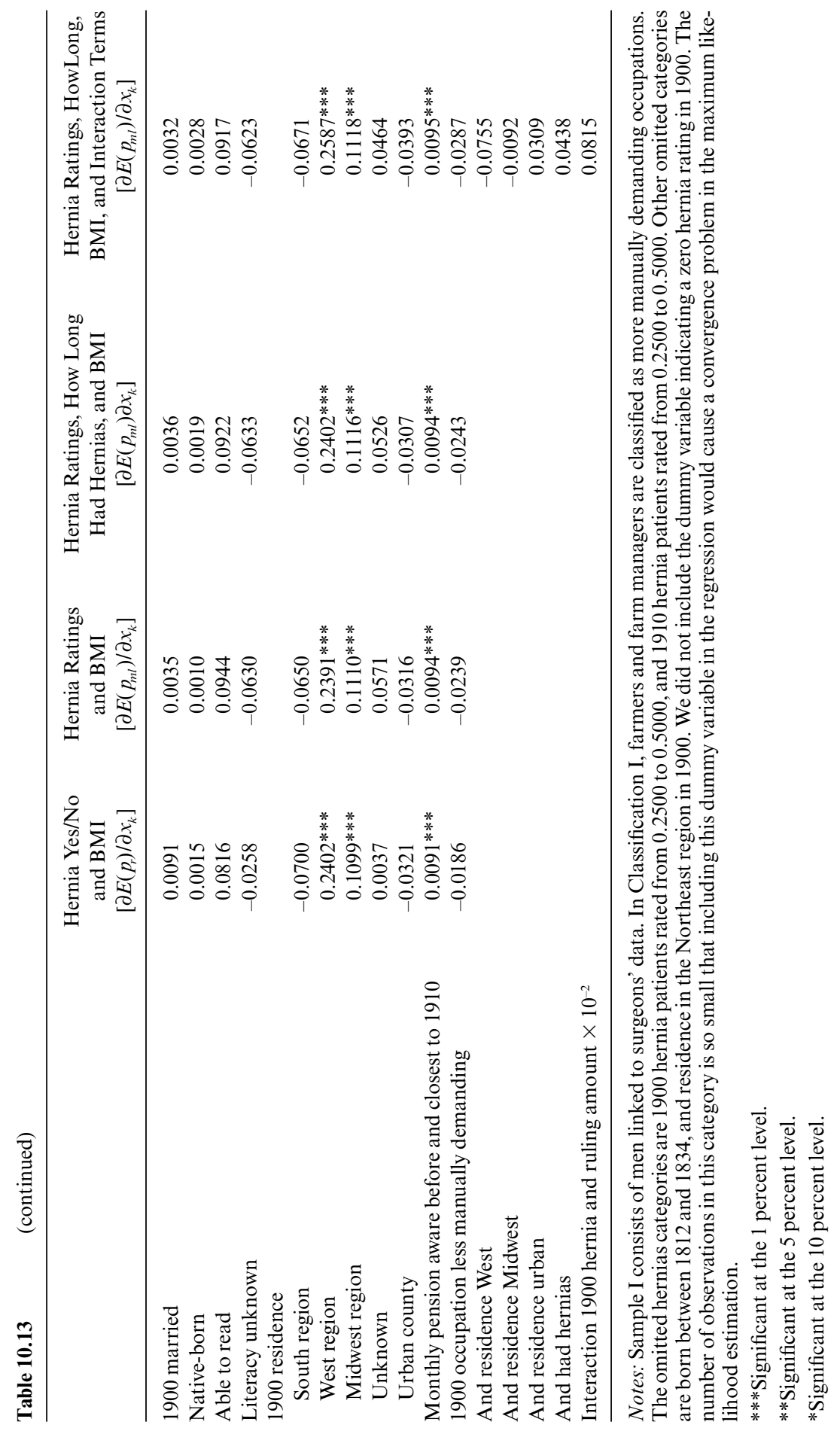




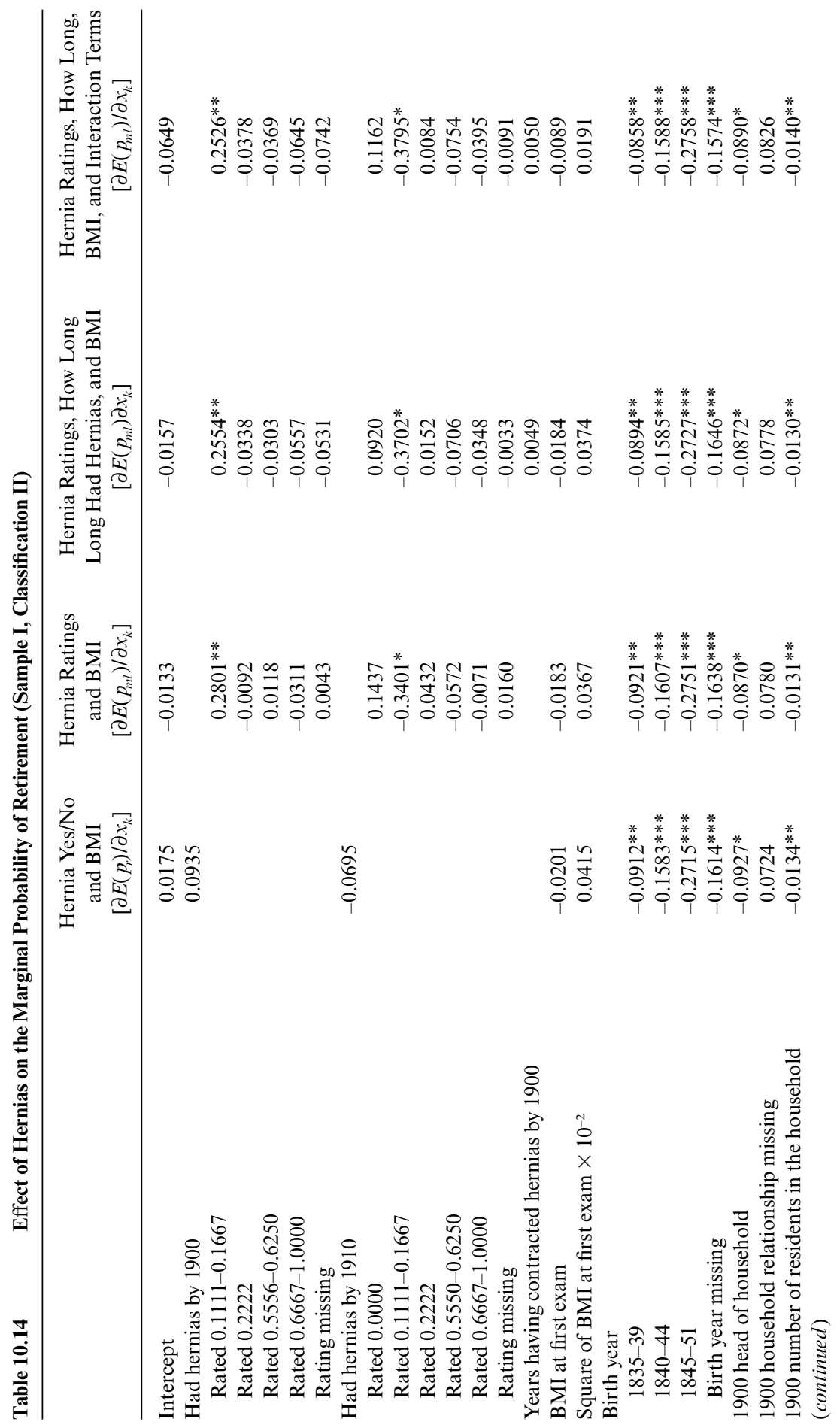




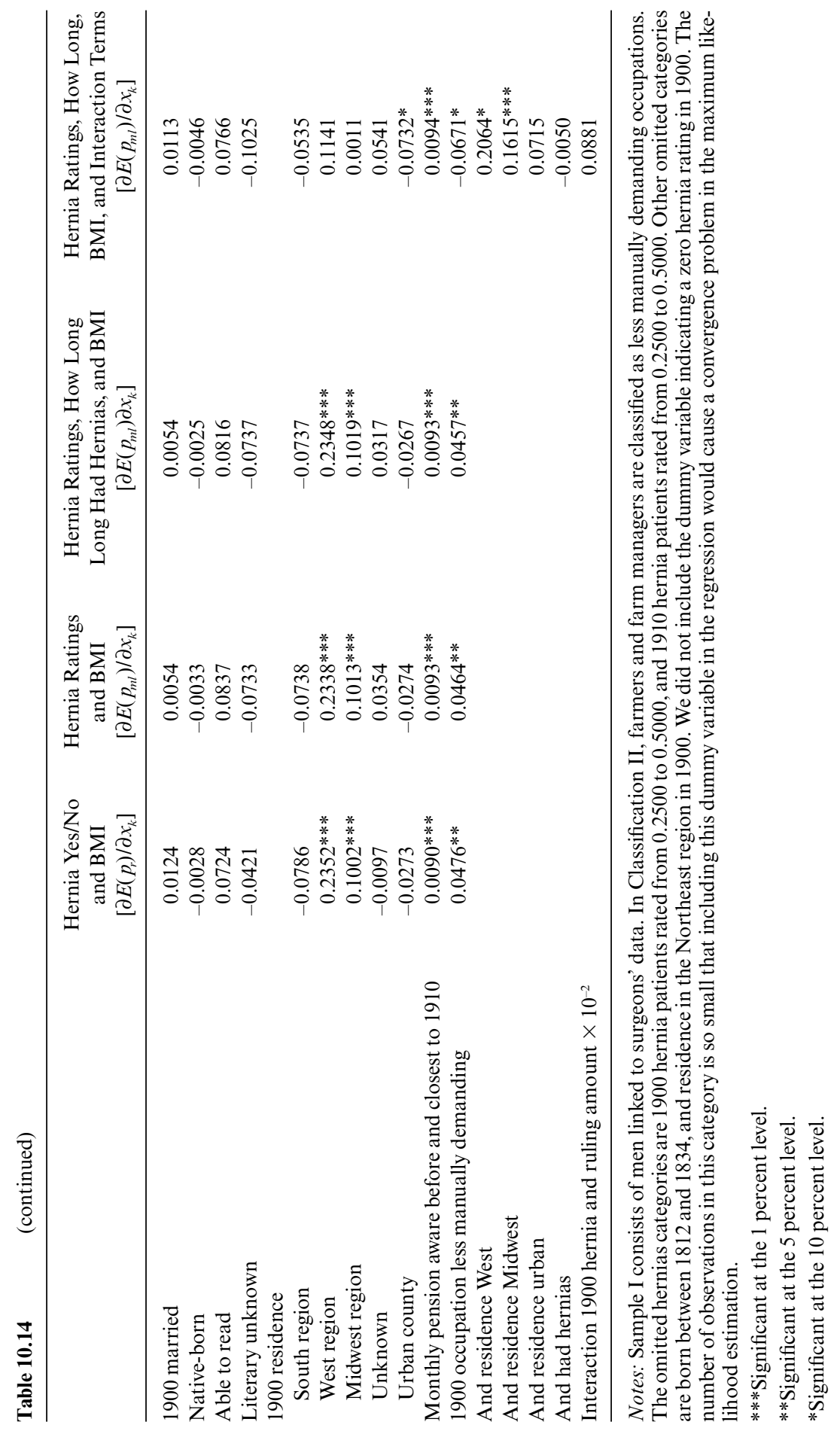


first model, where the zero-one past and contemporary hernia screens are considered, having hernias in 1900 increases the odds of retirement in 1910 by 10 percent. The coefficient has a marginal statistical significance. Because having hernias in 1900 positively correlates with having hernias in 1910, the coefficient estimate on the 1910 hernia screen variable is negative whenever the coefficient on the 1900 hernia screen variable is positive. In the second specification, where categorical dummies representing hernia ratings in 1900 and 1910 enter the regression, one group of hernia patients was influenced. Relative to those with median ratings (between 0.2500 and 0.5000 ) in 1900, patients having ratings of the least severe degree (between 0.1111 and 0.1667 ) in 1900 were 28 percent more likely to retire. Again, because of the positive correlation in ratings between 1900 and 1910, the coefficient estimate on the same group of patients (i.e., those having ratings of the least severe degree, between 0.1111 and 0.1667 , in 1910) is negative. We get the same qualitative result of the weak explanatory power of hernias when we add years of contracting into the equation. Although patients with longer hernia disability histories were more likely to retire, the coefficient estimate is small and insignificant. The result remains the same even after we add interaction terms of the 1900 hernia screen with the 1900 less manually demanding job dummy variable and with monthly pension income. No difference in retirement probability exists for hernia patients regardless of their 1900 job category and regardless of their income.

Table 10.14 presents the same models as table 10.13, except that farmers and farm managers are classified as less manually demanding occupations. The two classifications result in almost the same implications on health. Hernias did not exert a strong influence on retirement, after we have controlled for general health measured by a quadratic function of BMI. We have previously reasoned that if hernias were physically debilitating, retirement probability ought to be higher for patients in more manually demanding occupations: If they were to remain in the same occupational category, they had to endure the pain while providing physical labor. If they chose to switch to the less manually demanding occupations, they had to incur human capital investment, which could be a difficult option especially as they grew older. We have also reasoned that retirement probability ought to be higher for patients with higher income. Both table 10.13 and table 10.14 show a weak relationship between the degree of severity of hernias and the propensity to retire. They show no evidence of higher probability for patients in the more physically intensive occupations, or for patients with larger pension income.

Why did hernias have little effect on retirement? One possibility is that hernias caused impairment but that the impairment was not significant enough to cause disability. As table 10.3 indicates, more than 90 percent of patients had the usual inguinal hernias, more than 85 percent of the veterans had less morbid hernias (29.0 percent truss effective and 56.6 percent 
reducible), more than 80 percent had a single hernia, and less than 40 percent had hernias of size three inches or up. Although the majority of the patients had hernias that were probably discomforting, they resorted to crude but effective methods to cope with the disability, such as wearing trusses or other supportable materials that they made themselves. These coping methods likely reflect a greater importance of income relative to comfort. Why did the least severe kind of hernias (rated between 0.1111 and 0.1667 ) result in a higher rate of retirement? If we assume that the majority of patients who developed hernias developed small hernias initially, then we can reason that perhaps those who were likely to retire, retired upon the initial development of a hernia, while those who were less likely to retire endured their hernias.

Table 10.13 and table 10.14 also give similar effects of age, income, and household characteristics on labor force transitions of veterans between 1900 and 1910. Age is a highly significant factor in the labor force participation of the Civil War veterans. Relative to the oldest veterans, those born in later cohorts are less likely to retire. Heads of households and recruits with larger families were less likely to retire because they had stronger financial obligations that kept them in the labor force. We have previously concluded that for hernia patients, there was no income effect in addition to the income effect that might have existed for all veterans. There did exist a strong income effect for all veterans: An increase of one dollar per month in the pension award increases the retirement probability by almost 1 percentage point.

Tables 10.10 and 10.13 show a strong regional effect on retirement in the first three models. Relative to those residing in the Northeast region, veterans from the West and the Midwest regions are more likely to retire. A large population of farm laborers and farm owners resided in the West and the Midwest regions. Compared to the industrial Northeast, where employment opportunities were ample, they might have fewer choices in the types of low-stress jobs that they could switch to. To investigate the possibility that the observed regional effect in the West and the Midwest was due to the lack of substitute occupations for farm-related work, we include interaction terms between the dummy variable of less manually demanding occupations with the West and the Midwest regional dummy variables and with the urban county dummy variable.

Table 10.13 shows that when farmers and farm managers are classified as more manually demanding occupations, coefficient estimates on regional interaction terms and on the urban interaction term are not statistically significant. This result indicates that under Classification I, regional effect did not originate from geographical distribution of occupations. However, under Classification II, where farmers and farm managers are classified as less manually demanding occupations, coefficient estimates in table 10.14 show that residing in the West or the Midwest per se did not have any impact on 
retirement probability. Instead, only those West or Midwest residents who belonged to the less manually demanding group were more likely to retire. Comparing the last model in table 10.14 with that in table 10.13 , we conjecture that it was only the farmers and the farm managers in the West and the Midwest who had fewer occupational alternatives, because their knowledge was tied to the farm. As table 10.14 shows, once they left farming, they could not have easily acquired the skills of other less manually demanding jobs so that the only choice was to retire. In contrast, as table 10.13 shows, everything else being equal, farm laborers in the West and the Midwest had equal probability of retiring as others, because if they quit working on the farm, they could still engage in other physically intensive occupations. ${ }^{20}$

Finally, veterans in less manually demanding occupations were less likely to retire. This result was weak and insignificant when farmers and farm managers are grouped as more manually demanding jobs in table 10.13 , but was strong and significant when they are grouped as less manually demanding jobs in table 10.14. This result confirms the argument that switching costs were higher for those individuals engaging in more manually demanding occupations because they had to invest in additional human capital.

We have studied retirement for a sample of men with hernias versus men with hernias but with other disabilities. An alternative sample of interest to us is that of men with hernias versus healthy men without any surgeons' records. Tables 10.15 through 10.18 present the effect of hernias on retirement using this alternative sample. Because more than half of the healthy men did not have any medical examination, we do not have information on health and demographic characteristics for them. Therefore, as the last column of tables 10.15 and 10.17 show, 56.51 percent of the sample has missing birth years, 54.57 percent of the sample has missing household relationships, marital status, literacy, and residence, and 54.94 percent of the sample has missing nativity.

Despite the lack of information for a large number of men, tables 10.16 and 10.18 demonstrate results that are comparable to those in tables 10.13 and 10.14 in both sign and magnitude. The yes/no hernia screen variable indicates that having hernias by 1900 increases the odds of retirement by about 10 percent. The ratings variables indicate that having hernias of the least severe kind has an influence on retirement. Overall, the effect of hernias on retirement is weak. Younger cohorts born between 1840 and 1851 were less likely to retire compared to older cohorts, as were men with larger numbers of household residents to support and men living in urban counties where there were plenty of job opportunities. Farmers in the Midwest

20. With regard to region, retirement may be defined differently for farm or business owners than for individuals who were not owners. It is possible that farm and business owners never really retired. Even though they passed their businesses to the next generation, they maintained advisory roles. I thank Peter Blanck for bringing up this point. 


\begin{tabular}{|c|c|c|c|}
\hline & $\begin{array}{l}418 \text { Veterans in } \\
\text { Less Manually } \\
\text { Demanding } \\
\text { Professions }\end{array}$ & $\begin{array}{l}1,486 \text { Veterans in } \\
\text { More Manually } \\
\text { Demanding } \\
\text { Professions }\end{array}$ & $\begin{array}{l}\text { Overall (both more } \\
\text { and less manually } \\
\text { demanding } \\
\text { professions) }\end{array}$ \\
\hline 1900 in labor force, 1910 retired & 22.25 & 23.89 & 23.53 \\
\hline Had hernias by 1900 & 12.20 & 13.86 & 13.50 \\
\hline Rated 0.0000 & 0 & 0.27 & 0.21 \\
\hline Rated $0.1111-0.1667$ & 0.72 & 1.08 & 1.00 \\
\hline Rated 0.2222 & 1.91 & 1.68 & 1.73 \\
\hline Rated $0.2500-0.5000$ & 3.83 & 3.90 & 3.89 \\
\hline Rated $0.5556-0.6250$ & 1.67 & 0.22 & 2.10 \\
\hline Rated $0.6667-1.0000$ & 0.72 & 1.08 & 1.00 \\
\hline Rating missing & 3.35 & 3.63 & 3.57 \\
\hline Had hernias by 1910 & 17.70 & 18.30 & 18.17 \\
\hline Rated 0.0000 & 0.96 & 0.07 & 0.26 \\
\hline Rated $0.1111-0.1667$ & 0 & 0.61 & 0.47 \\
\hline Rated 0.2222 & 0.72 & 0.94 & 0.89 \\
\hline Rated $0.2500-0.5000$ & 1.67 & 1.41 & 1.47 \\
\hline Rated $0.5556-0.6250$ & 0.72 & 1.82 & 1.58 \\
\hline Rated $0.6667-1.0000$ & 0.48 & 0.94 & 0.84 \\
\hline Rating missing & 13.16 & 12.52 & 12.66 \\
\hline \multicolumn{4}{|l|}{ Years having contracted hernias } \\
\hline by 1900 & 1.42 & 1.54 & 1.51 \\
\hline \multicolumn{4}{|l|}{ Birth year } \\
\hline $1812-34$ & 3.11 & 3.36 & 3.31 \\
\hline $1835-39$ & 6.70 & 9.08 & 8.56 \\
\hline $1840-44$ & 27.51 & 19.25 & 21.06 \\
\hline $1845-51$ & 11.48 & 10.30 & 10.56 \\
\hline Birth year missing & 51.20 & 58.01 & 56.51 \\
\hline 1900 head of household & 47.61 & 41.52 & 42.86 \\
\hline \multicolumn{4}{|l|}{1900 household relationship } \\
\hline missing & 48.56 & 56.26 & 54.57 \\
\hline \multicolumn{4}{|l|}{1900 number of residents if } \\
\hline number nonmissing & 1.64 & 1.52 & 1.54 \\
\hline 1900 married & 46.65 & 38.43 & 40.23 \\
\hline 1900 marital status missing & 48.56 & 56.26 & 54.57 \\
\hline Native-born & 45.93 & 38.90 & 40.44 \\
\hline Nativity missing & 48.56 & 56.46 & 54.73 \\
\hline Able to read & 51.43 & 41.92 & 44.01 \\
\hline Literacy unknown & 48.56 & 56.26 & 54.57 \\
\hline \multicolumn{4}{|l|}{1900 residence } \\
\hline Northeast region & 13.16 & 13.86 & 13.71 \\
\hline South region & 0.96 & 1.82 & 1.63 \\
\hline West region & 3.83 & 1.08 & 1.68 \\
\hline Midwest region & 32.54 & 26.99 & 28.20 \\
\hline Unknown & 48.56 & 56.26 & 54.57 \\
\hline Urban county & 20.10 & 9.56 & 11.87 \\
\hline Urban county missing & 49.76 & 56.39 & 54.94 \\
\hline $\begin{array}{l}\text { Monthly pension award before } \\
\text { and closest to } 1910^{\mathrm{a}}\end{array}$ & $\$ 7.38$ & $\$ 7.17$ & $\$ 7.22$ \\
\hline
\end{tabular}

Notes: Dummies in percentages. Sample II consists of 1,558 men linked to surgeons' data and 346 hernia patients. In Classification I, farmers and farm managers are classified as more manually demanding occupations.

af a recruit did not apply for pension, or if he applied and did not get any pension, his monthly pension is zero. The average monthly pension award for 215 recruits in 1900 less manually demanding occupation who did get awarded is $\$ 14.36$, for 713 recruits in 1900 more manually demanding occupation who did get awarded is $\$ 14.95$, and for the overall 928 recruits who did get awarded is $\$ 14.81$. 


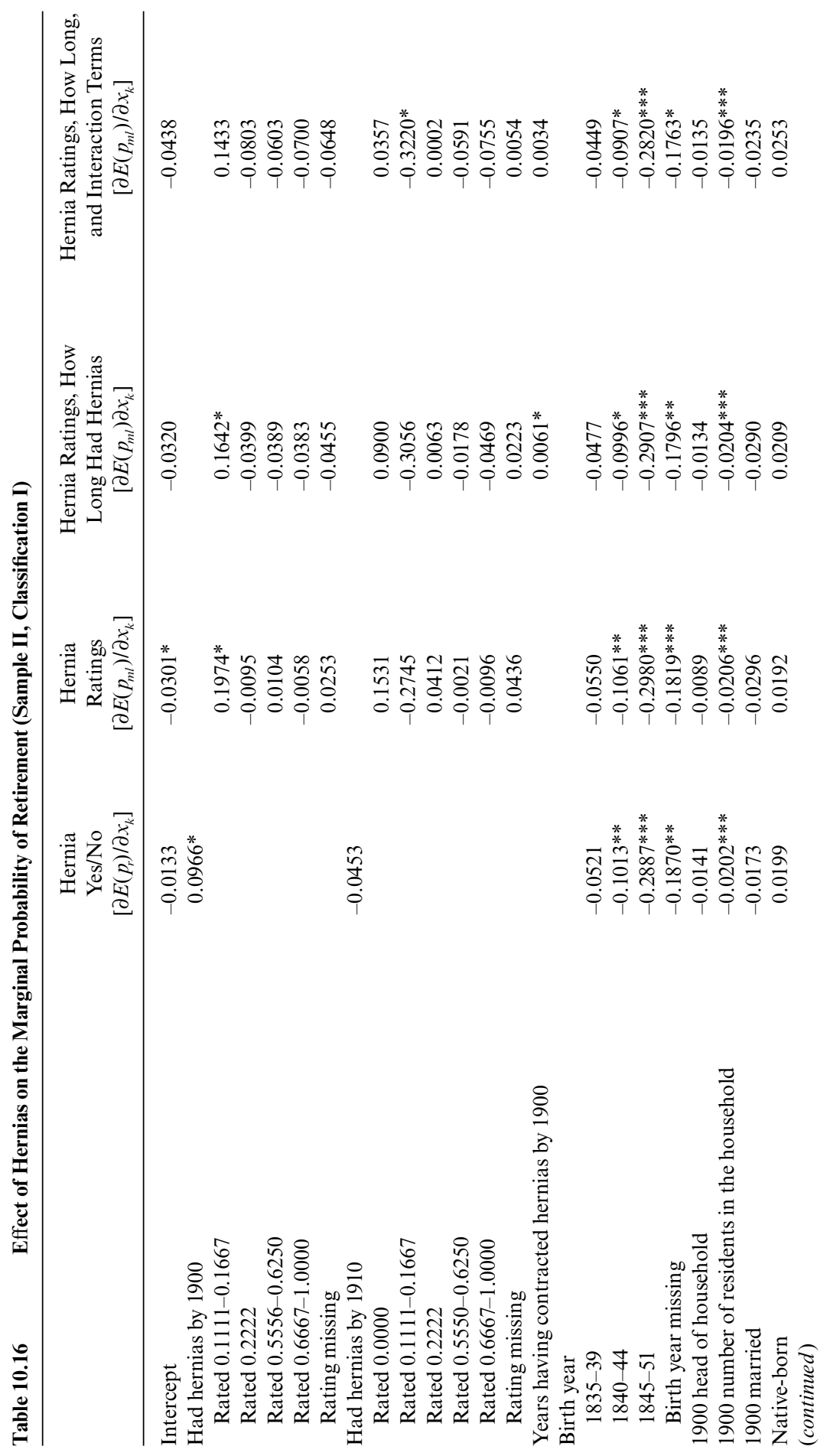




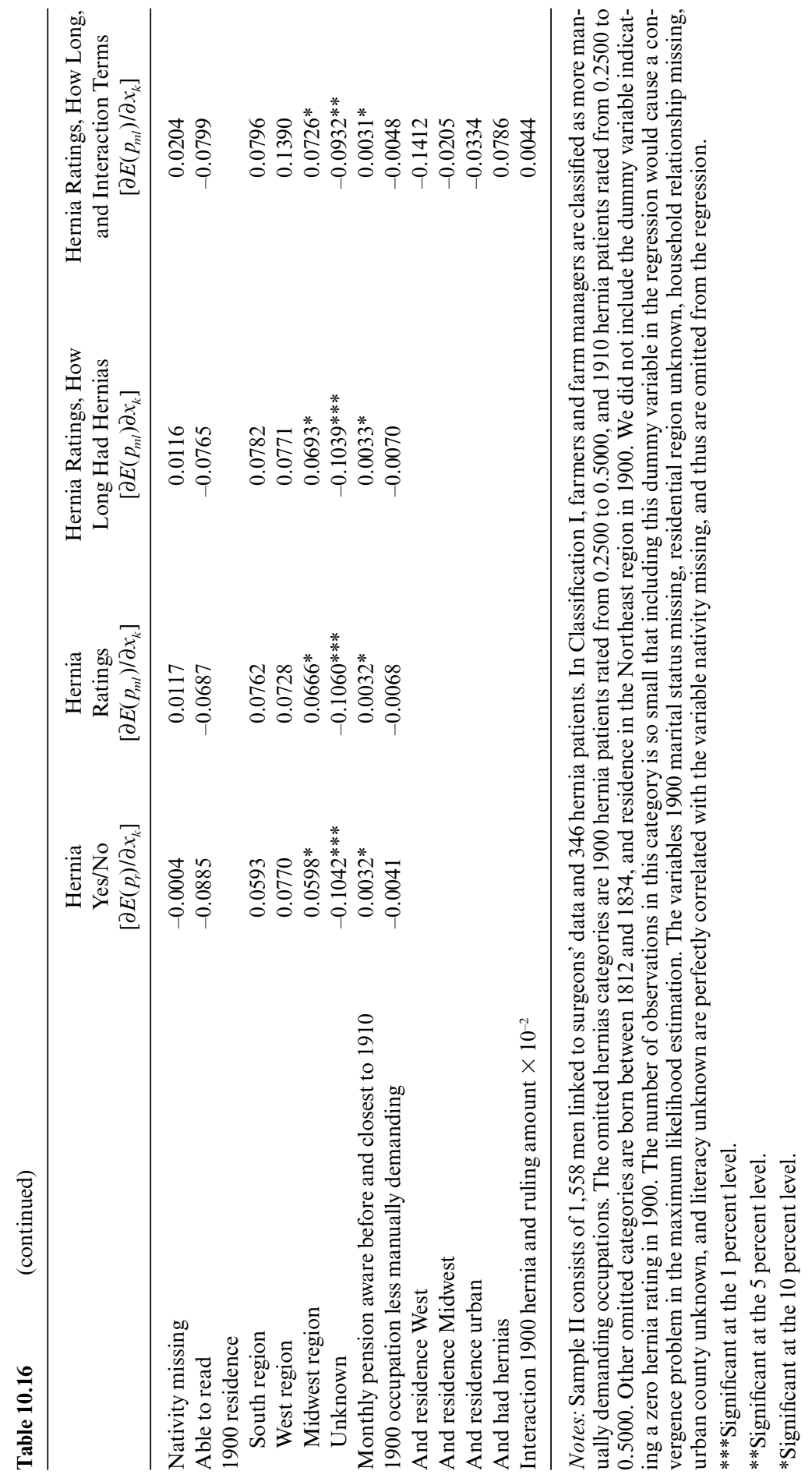




\begin{tabular}{|c|c|c|c|}
\hline & $\begin{array}{c}\text { 1,243 Veterans in } \\
\text { Less Manually } \\
\text { Demanding } \\
\text { Professions }\end{array}$ & $\begin{array}{l}661 \text { Veterans in } \\
\text { More Manually } \\
\text { Demanding } \\
\text { Professions }\end{array}$ & $\begin{array}{c}\text { Overall (both more } \\
\text { and less manually } \\
\text { demanding } \\
\text { professions) }\end{array}$ \\
\hline 1900 in labor force, 1910 retired & 24.22 & 22.24 & 23.53 \\
\hline Had hernias by 1900 & 12.63 & 15.13 & 13.50 \\
\hline Rated 0.0000 & 0.16 & 0.30 & 0.21 \\
\hline Rated $0.1111-0.1667$ & 0.88 & 1.21 & 1.00 \\
\hline Rated 0.2222 & 1.85 & 1.51 & 1.73 \\
\hline Rated $0.2500-0.5000$ & 4.10 & 3.48 & 3.89 \\
\hline Rated $0.5556-0.6250$ & 1.85 & 2.57 & 2.10 \\
\hline Rated $0.6667-1.0000$ & 0.97 & 1.06 & 1.00 \\
\hline Rating missing & 2.82 & 4.99 & 3.57 \\
\hline Had hernias by 1910 & 16.65 & 21.03 & 18.17 \\
\hline Rated 0.0000 & 0.40 & 0 & 0.26 \\
\hline Rated $0.1111-0.1667$ & 0.32 & 0.76 & 0.47 \\
\hline Rated 0.2222 & 1.13 & 0.45 & 0.89 \\
\hline Rated $0.2500-0.5000$ & 1.29 & 1.82 & 1.47 \\
\hline Rated $0.5550-0.6250$ & 1.29 & 2.12 & 1.58 \\
\hline Rated $0.6667-1.0000$ & 0.80 & 0.91 & 0.84 \\
\hline Rating missing & 11.42 & 14.98 & 12.66 \\
\hline \multicolumn{4}{|l|}{ Years having contracted hernias } \\
\hline by 1900 & 1.37 & 1.78 & 1.51 \\
\hline \multicolumn{4}{|l|}{ Birth year } \\
\hline $1812-34$ & 3.22 & 3.48 & 3.31 \\
\hline $1835-39$ & 7.88 & 9.83 & 8.56 \\
\hline $1840-44$ & 21.56 & 20.12 & 21.06 \\
\hline $1845-51$ & 9.41 & 12.71 & 10.56 \\
\hline Birth year missing & 57.42 & 53.86 & 56.51 \\
\hline 1900 head of household & 42.00 & 44.48 & 42.86 \\
\hline \multicolumn{4}{|l|}{1900 household relationship } \\
\hline missing & 56.40 & 51.13 & 54.57 \\
\hline \multicolumn{4}{|l|}{1900 number of residents if } \\
\hline number nonmissing & 1.51 & 1.60 & 1.54 \\
\hline 1900 married & 39.90 & 40.85 & 40.23 \\
\hline 1900 marital status missing & 56.40 & 51.13 & 54.57 \\
\hline Native-born & 39.58 & 42.06 & 40.44 \\
\hline Nativity missing & 56.56 & 51.29 & 54.73 \\
\hline Able to read & 42.88 & 46.14 & 44.01 \\
\hline Literacy unknown & 56.40 & 51.13 & 54.57 \\
\hline \multicolumn{4}{|l|}{1900 residence } \\
\hline Northeast region & 10.06 & 20.57 & 13.71 \\
\hline South region & 1.77 & 1.36 & 1.63 \\
\hline West region & 2.01 & 1.06 & 1.68 \\
\hline Midwest region & 29.44 & 25.87 & 28.20 \\
\hline Unknown & 56.40 & 51.13 & 54.57 \\
\hline Urban county & 9.25 & 16.79 & 11.87 \\
\hline Urban county missing & 56.88 & 51.29 & 54.94 \\
\hline \multicolumn{4}{|l|}{ Nonmissing monthly pension before } \\
\hline and closest to $1910^{\mathrm{a}}$ & $\$ 7.06$ & $\$ 7.52$ & $\$ 7.22$ \\
\hline
\end{tabular}

Notes: Dummies in percentages. Sample II consists of 1,558 men linked to surgeons' data and 346 hernia patients. In Classification II, farmers and farm managers are classified as less manually demanding occupations.

aIf a recruit did not apply for pension, or if he applied and did not get any pension, his monthly pension is zero. The average monthly pension award for 583 recruits in 1900 less manually demanding occupation who did get awarded is $\$ 15.04$, for 345 recruits in 1900 more manually demanding occupation who did get awarded is $\$ 14.41$, and for the overall 928 recruits who did get awarded is $\$ 14.81$. 


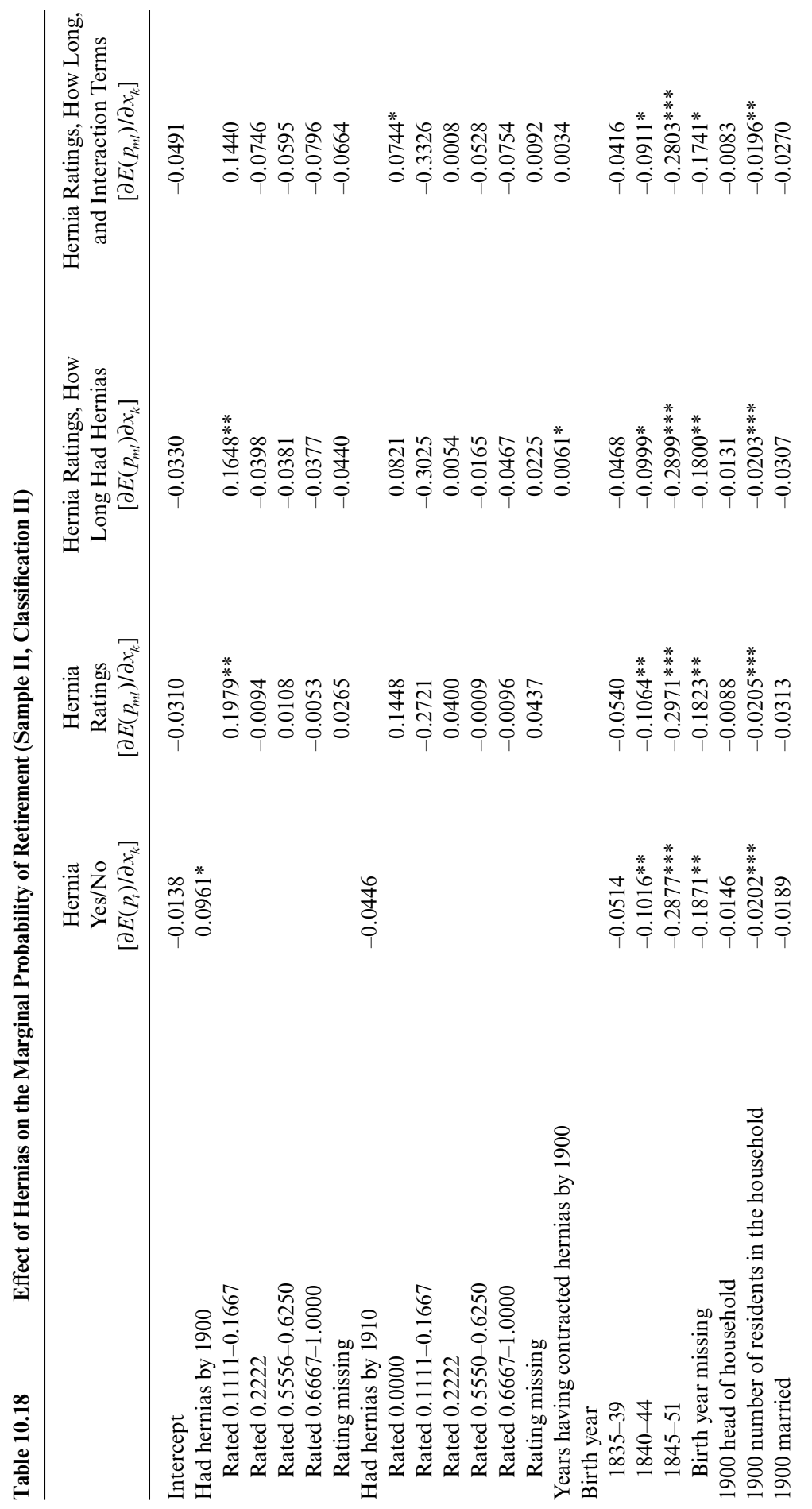




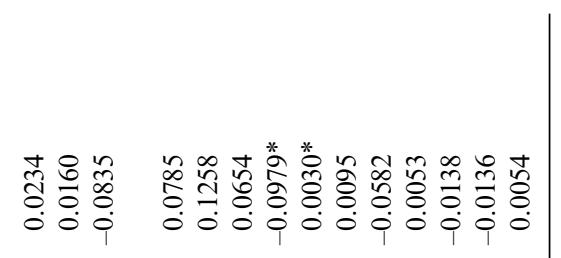

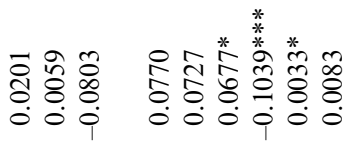

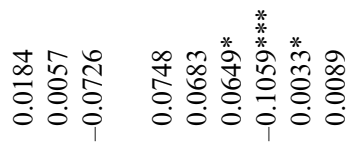

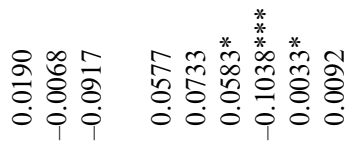

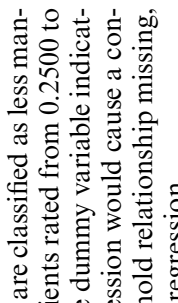

要

要

要

䓫. है

주을

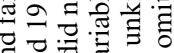

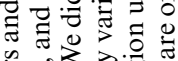

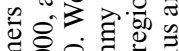

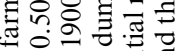

$=0 . \Xi$.

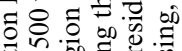

त

O일

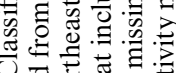

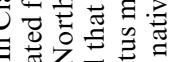

踏 $Z=$

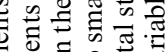

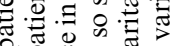

, 记

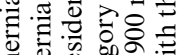

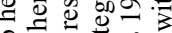

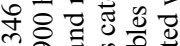

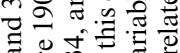

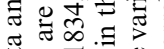

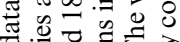

당

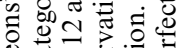

品

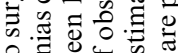

일

च记

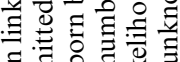

흥 응

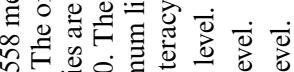

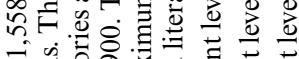

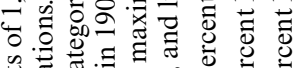

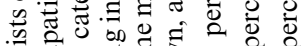

कू

웡.

实 on:

눈

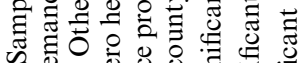
นึ

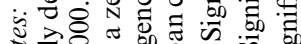

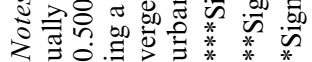


region were more likely to retire, as were men receiving higher monthly pension awards.

Yet another sample to test the robustness of the previous results is the sample containing only men in 1900 manually demanding occupations who had surgeons' records. As described before, we group men into three types of jobs according to physical intensity. Tables 10.19 through 10.22 show results pertaining to this sample. Comparing table 10.20 to tables 10.13 and 10.16, we notice two qualitative differences. First, the yes/no hernia screen variable ceases to be significant. The low explanatory power of hernia screen is likely due to the fact that the screen variable is only a very coarse measure of debilitation. When ratings are used instead, we get a result that is consistent with that from the other samples: Those in the lowest hernia ratings were significantly more likely to retire.

Second, with the interaction terms of physical intensity and other dummy variables, those in 1900 with very physically intensive jobs were more likely to retire, as panel A of table 10.20 indicates. Furthermore, panel $\mathrm{B}$ shows that veterans in the skilled occupations were less likely to retire. Those results are consistent with the theory by Ransom and Sutch (1986) of "downward occupational mobility" that predicts higher labor market exit rates for the unskilled. There is a significantly negative marginal effect on men engaging in physically intensive jobs and living in the West or the Midwest region. Those men were primary farm laborers who could not afford to retire and who were limited in alternative occupational choices. In contrast, there is a significantly positive marginal effect on skilled farm managers living in the West or the Midwest region.

Results in tables 10.21 and 10.22 relate to the investigation of 688 men who were a subsample of the 1,474 men in tables 10.19 and 10.20. Men excluded are farm owners and farm managers. The A panels of tables 10.22 and 10.20 are comparable, as are their B panels. A few variables such as regional dummies and interaction terms cease to be significant because of a much smaller sample size. Overall, using the sample of men in 1900 manually demanding occupations, we find a weak positive effect of hernia severity on retirement, positive age and income effects on retirement, and negative household-size and head-of-household effects on retirement.

\subsection{Conclusions and Future Work}

One of the challenging aspects in empirical studies on health and labor supply is the construction of an accurate measure of health status. Promising candidates for this measure include life expectancy, mortality rate, height, and BMI, and composite indicators of infectious diseases or chronic disabilities. As noted by Costa (1996, 64), "the difficulty in using life expectancy as a health measure is that life expectancies can be high and health poor if advances in medical technology have led to an increased burden 


\begin{tabular}{|c|c|}
\hline Variable & Mean (dummies in \%) \\
\hline 1900 in labor force, 1910 retired & 25.44 \\
\hline Had hernias by 1900 & 13.98 \\
\hline Rated 0.0000 & 0.27 \\
\hline Rated $0.1111-0.1667$ & 1.09 \\
\hline Rated 0.2222 & 1.70 \\
\hline Rated $0.2500-0.5000$ & 3.93 \\
\hline Rated $0.5556-0.6250$ & 2.24 \\
\hline Rated $0.6667-1.0000$ & 1.09 \\
\hline Rating missing & 3.66 \\
\hline Had hernias by 1910 & 18.45 \\
\hline Rated 0.0000 & 0.07 \\
\hline Rated $0.1111-0.1667$ & 0.61 \\
\hline Rated 0.2222 & 0.95 \\
\hline Rated $0.2500-0.5000$ & 1.42 \\
\hline Rated $0.5550-0.6250$ & 1.83 \\
\hline Rated $0.6667-1.0000$ & 0.95 \\
\hline Rating missing & 12.62 \\
\hline Years having contracted hernias by 1900 & 1.55 \\
\hline BMI at first exam & 22.87 \\
\hline Square of BMI at first exam & 529.71 \\
\hline \multicolumn{2}{|l|}{ Birth year } \\
\hline $1812-34$ & 8.68 \\
\hline $1835-39$ & 20.01 \\
\hline $1840-44$ & 44.84 \\
\hline $1845-51$ & 19.88 \\
\hline Birth year missing & 6.58 \\
\hline 1900 head of household & 92.33 \\
\hline 1900 household relationship missing & 3.26 \\
\hline 1900 number of residents in the household & 3.22 \\
\hline 1900 married & 87.25 \\
\hline Native-born & 84.53 \\
\hline Nativity missing & 3.60 \\
\hline Able to read & 92.47 \\
\hline Literacy unknown & 3.26 \\
\hline \multicolumn{2}{|l|}{1900 residence } \\
\hline Northeast region & 39.76 \\
\hline South region & 3.60 \\
\hline West region & 2.99 \\
\hline Midwest region & 50.34 \\
\hline Unknown & 3.26 \\
\hline Urban country & 20.69 \\
\hline County unknown & 3.32 \\
\hline \multicolumn{2}{|l|}{1900 occupation } \\
\hline Not Much Physically Intensive & 54.82 \\
\hline Somewhat Physically Intensive & 6.51 \\
\hline Very Physically Intensive & 38.67 \\
\hline Unskilled & 20.35 \\
\hline Skilled & 79.65 \\
\hline Monthly pension award before and closest to 1910 & $\$ 14.77$ \\
\hline
\end{tabular}

Notes: Sample III consists of men linked to surgeons' data who were in more manually demanding occupations in 1900. In Classification I, farmers and farm managers are classified as more manually demanding occupations. 


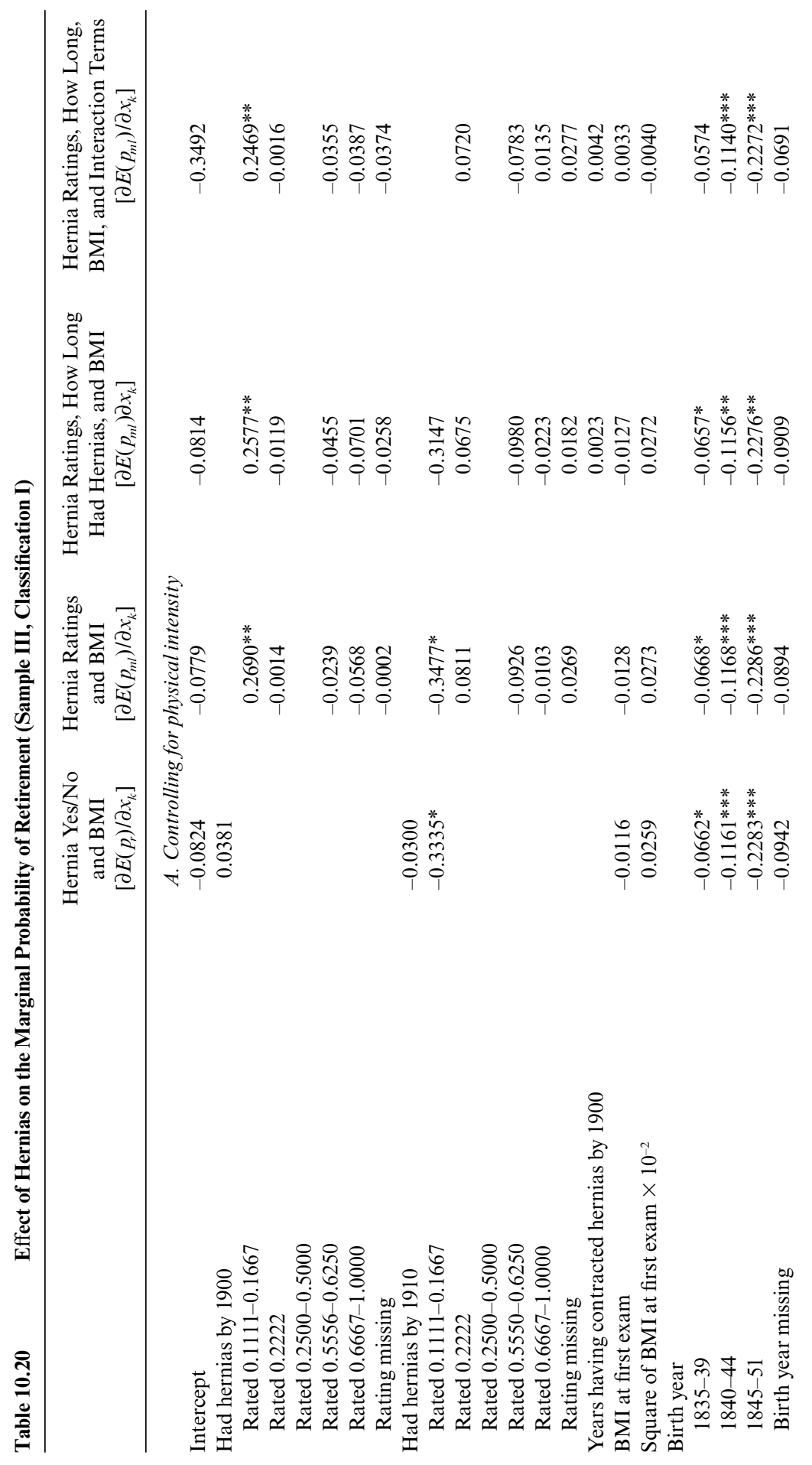




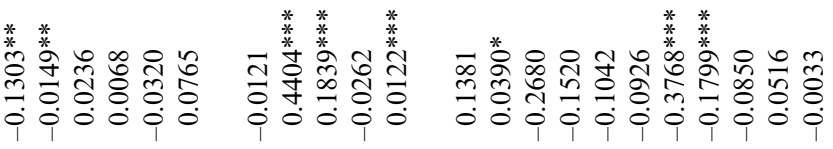

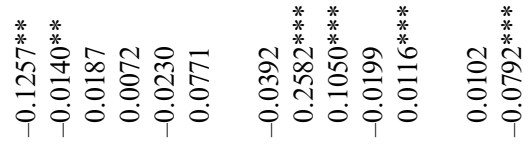

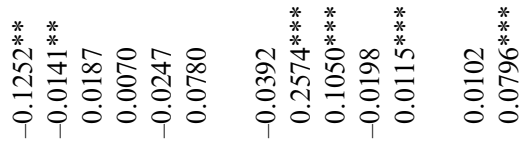

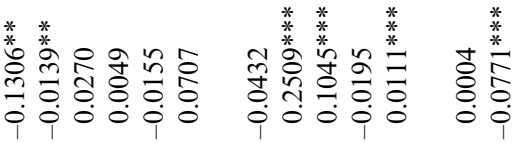

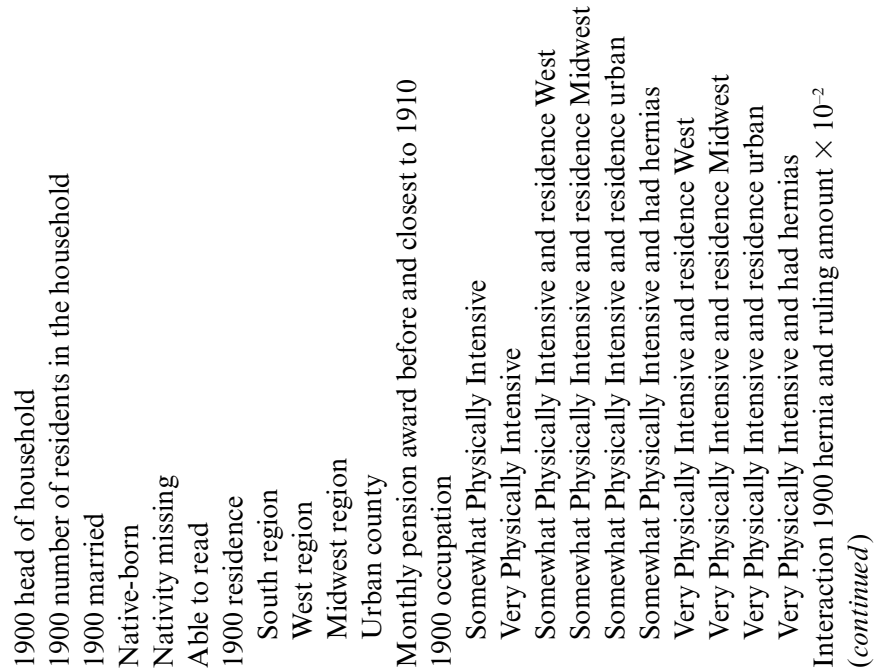




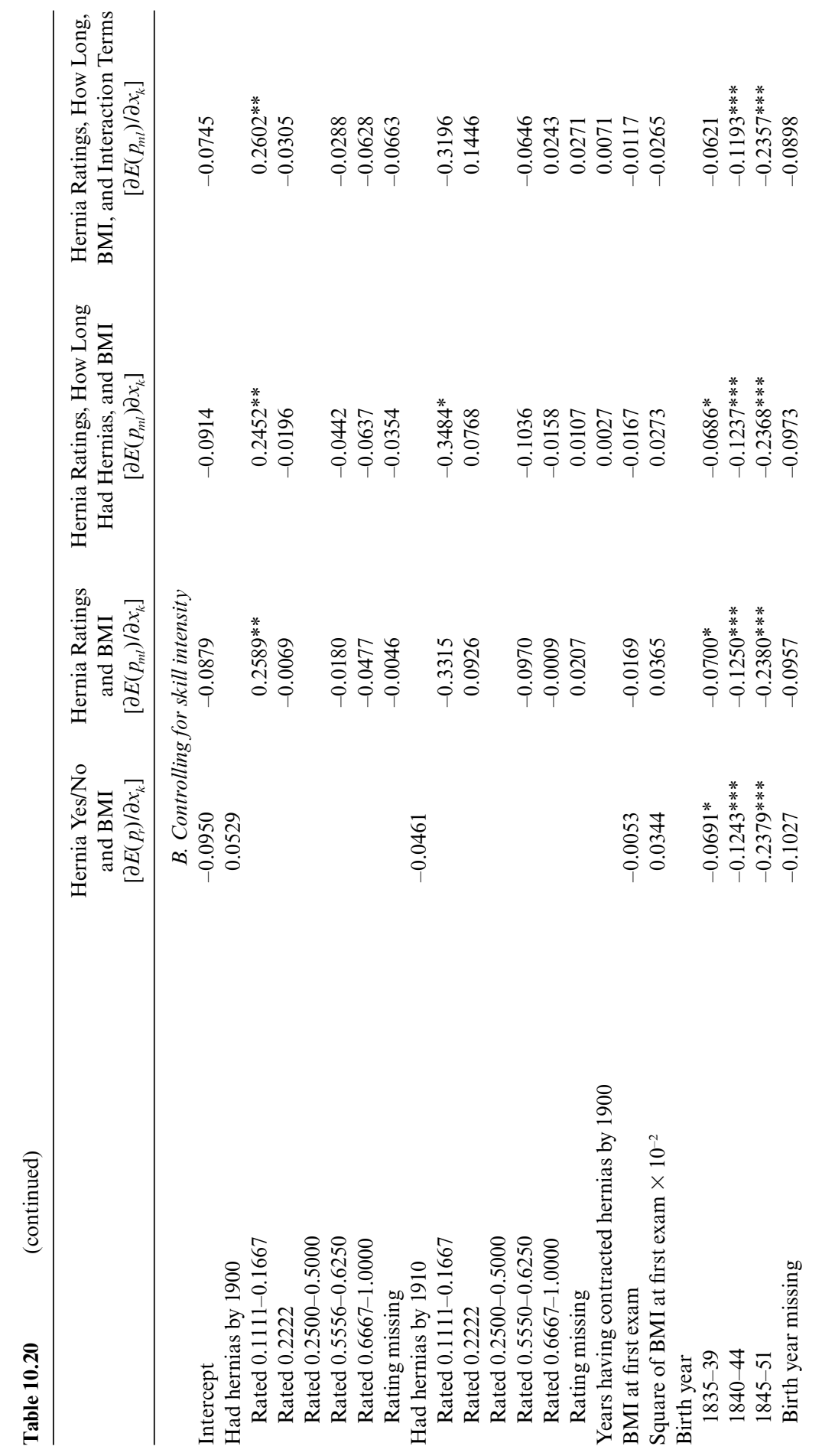




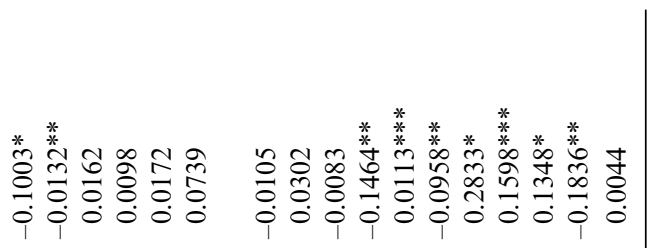

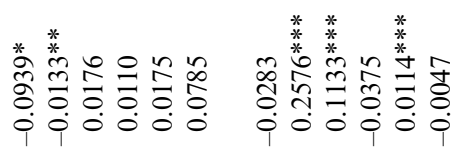

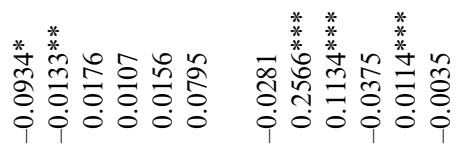

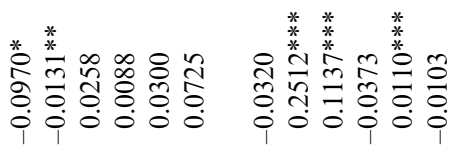

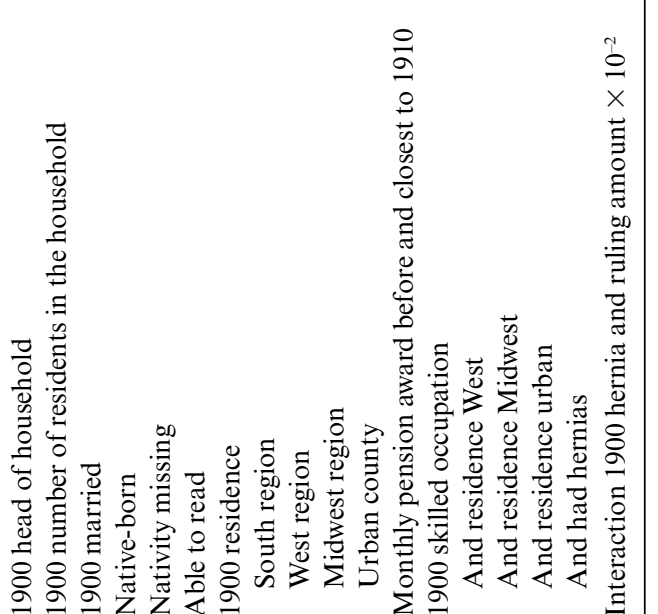

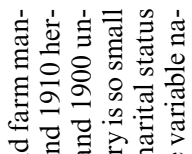

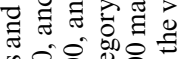

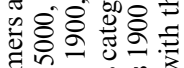

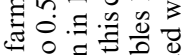

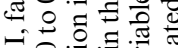

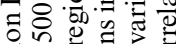

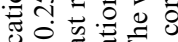

跑

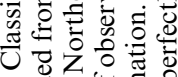

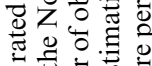

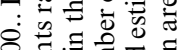

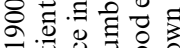

$\exists$ 政 를

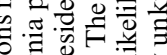

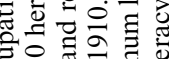

象完

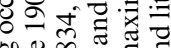

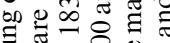

证

을.

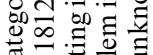

정

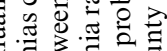

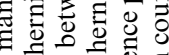

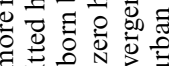

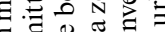

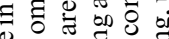

过

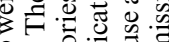

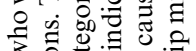

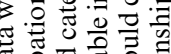

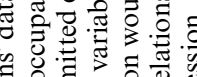

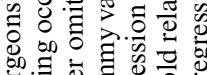

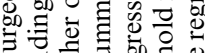

कि

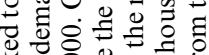

눙

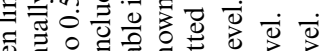

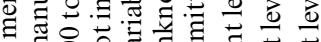

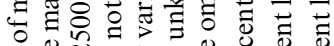

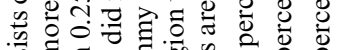

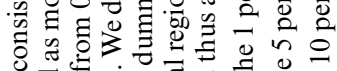

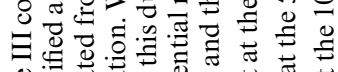

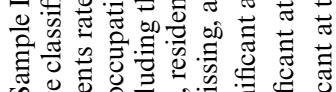
î

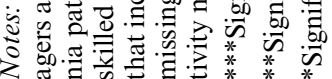




\begin{tabular}{|c|c|}
\hline Variable & Mean (dummies in \%) \\
\hline 1900 in labor force, 1910 retired & 20.93 \\
\hline Had hernias by 1900 & 14.53 \\
\hline Rated 0.0000 & 0.29 \\
\hline Rated $0.1111-0.1667$ & 1.16 \\
\hline Rated 0.2222 & 1.45 \\
\hline Rated $0.2500-0.5000$ & 3.34 \\
\hline Rated $0.5556-0.6250$ & 2.47 \\
\hline Rated $0.6667-1.0000$ & 1.02 \\
\hline Rating missing & 4.80 \\
\hline Had hernias by 1910 & 20.20 \\
\hline Rated 0.0000 & 0.00 \\
\hline Rated $0.1111-0.1667$ & 0.73 \\
\hline Rated 0.2222 & 0.44 \\
\hline Rated $0.2500-0.5000$ & 1.74 \\
\hline Rated $0.5550-0.6250$ & 2.03 \\
\hline Rated $0.6667-1.0000$ & 0.87 \\
\hline Rating missing & 14.39 \\
\hline Years having contracted hernias by 1900 & 1.71 \\
\hline BMI at first exam & 22.82 \\
\hline Square of BMI at first exam & 527.85 \\
\hline \multicolumn{2}{|l|}{ Birth year } \\
\hline $1812-34$ & 7.27 \\
\hline $1835-39$ & 18.60 \\
\hline $1840-44$ & 45.64 \\
\hline $1845-51$ & 21.37 \\
\hline Birth year missing & 7.12 \\
\hline 1900 head of household & 89.10 \\
\hline 1900 household relationship missing & 2.91 \\
\hline 1900 number of residents in the household & 3.12 \\
\hline 1900 married & 86.34 \\
\hline Native-born & 82.56 \\
\hline Nativity missing & 3.05 \\
\hline Able to read & 92.59 \\
\hline Literacy unknown & 2.91 \\
\hline \multicolumn{2}{|l|}{1900 residence } \\
\hline Northeast region & 51.45 \\
\hline South region & 2.33 \\
\hline West region & 3.63 \\
\hline Midwest region & 39.68 \\
\hline Unknown & 2.91 \\
\hline Urban country & 33.14 \\
\hline County unknown & 2.91 \\
\hline \multicolumn{2}{|l|}{1900 occupation classification } \\
\hline Not Much Physically Intensive & 3.20 \\
\hline Somewhat Physically Intensive & 13.95 \\
\hline Very Physically Intensive & 82.85 \\
\hline Unskilled & 43.60 \\
\hline Skilled & 56.40 \\
\hline Monthly pension award before and closest to 1910 & $\$ 14.57$ \\
\hline
\end{tabular}

Notes: Sample III consists of men linked to surgeons' data who were in more manually demanding occupations in 1900. In Classification II, farmers and farm managers are classified as less manually demanding occupations. 


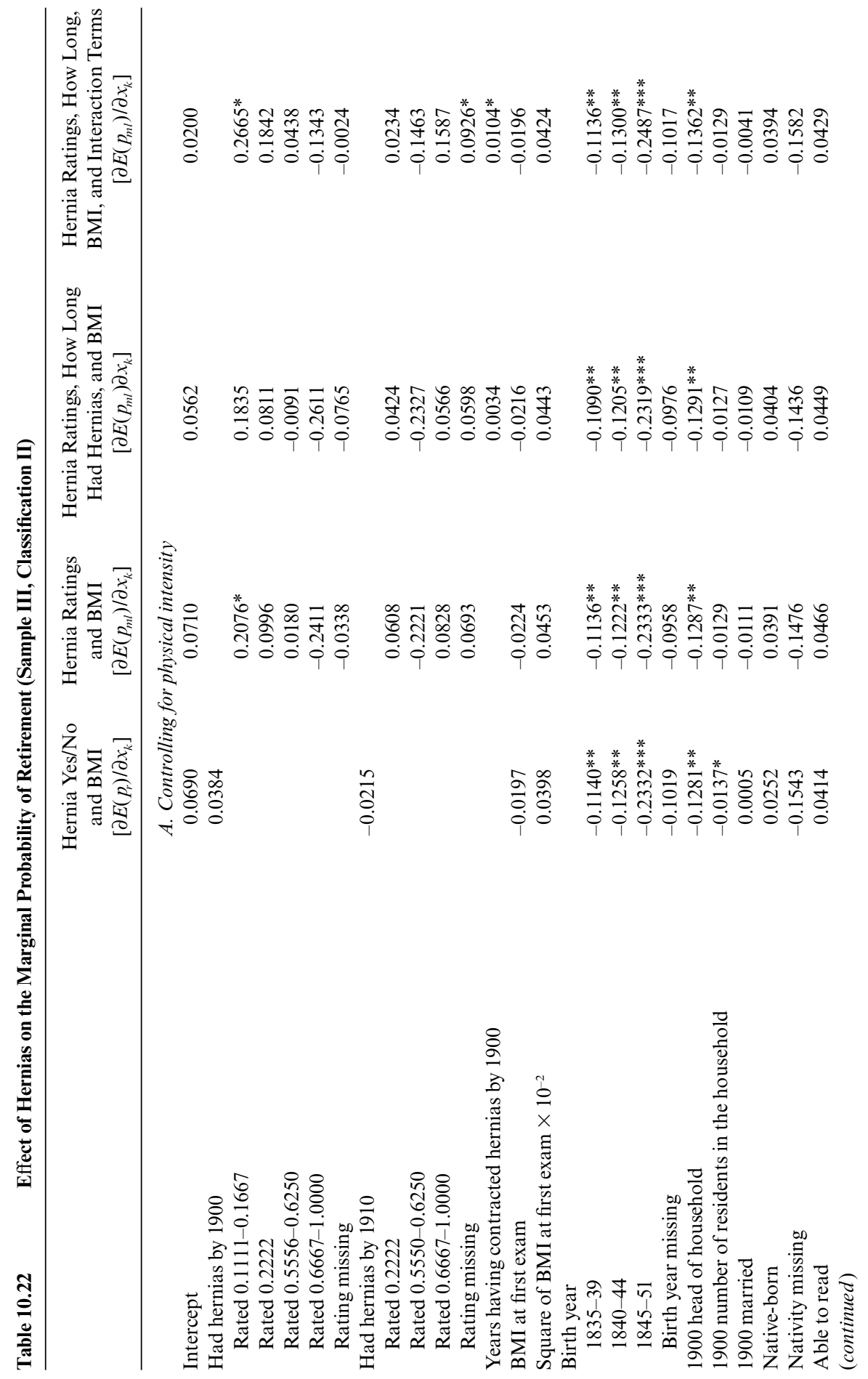




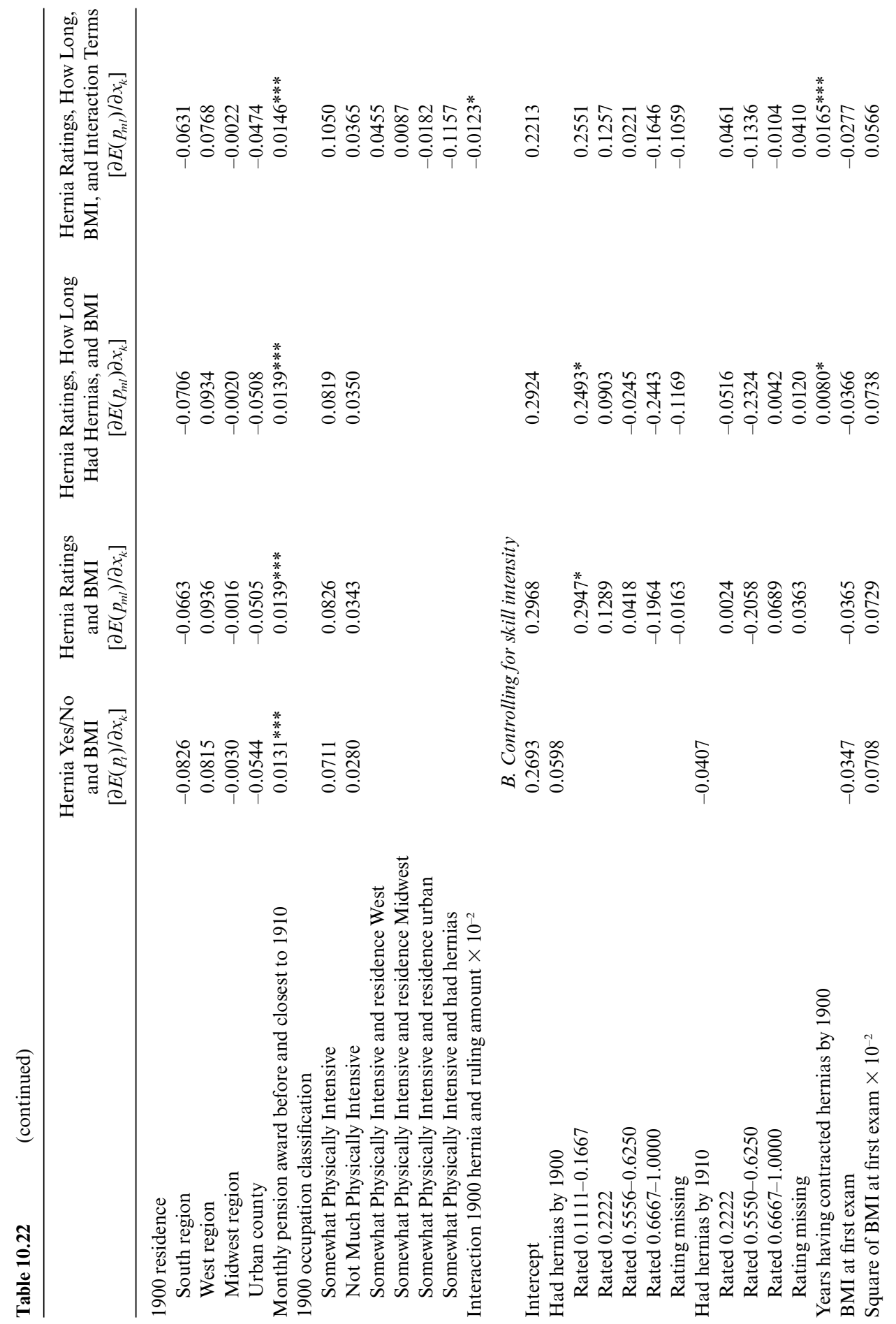




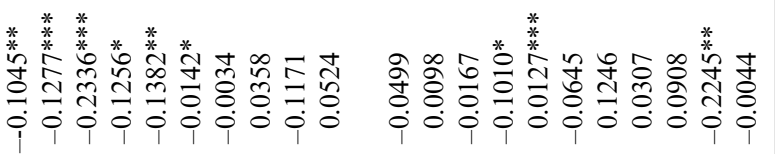

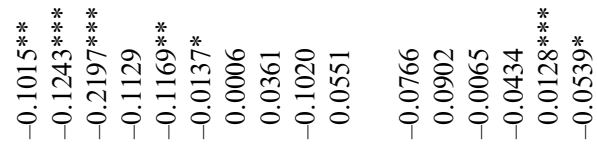

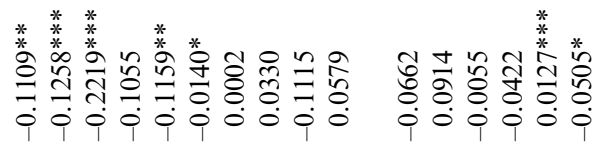

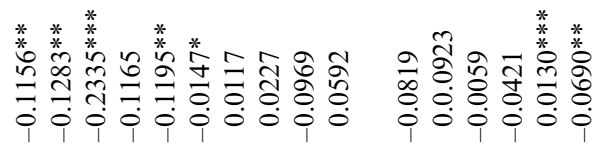

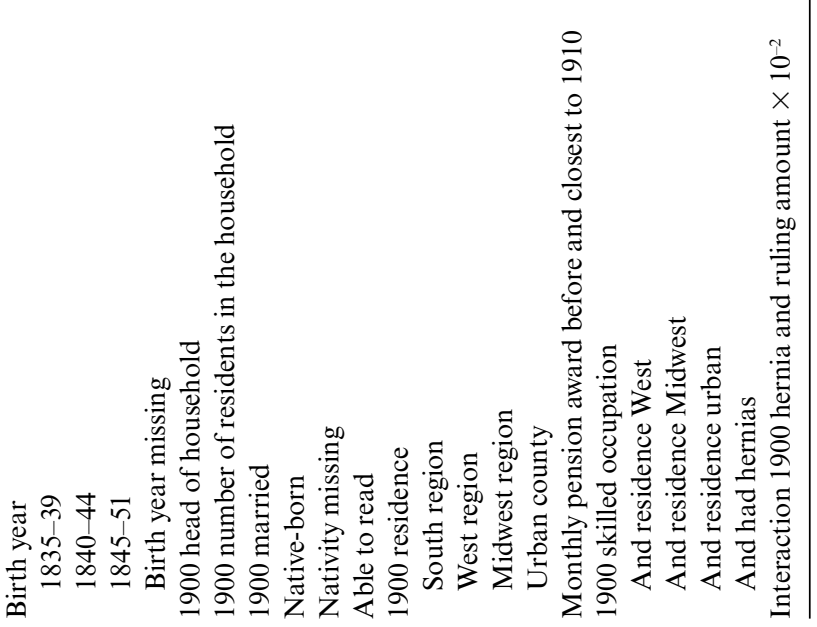

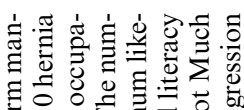

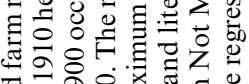

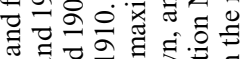

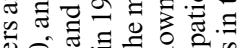

造造造.

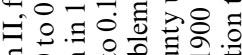

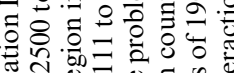

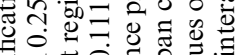

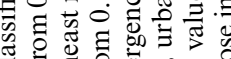

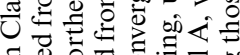

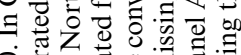

家象

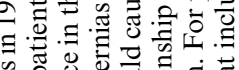

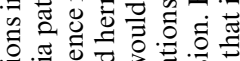

.

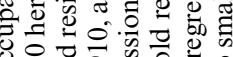

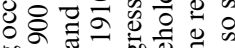

on 0

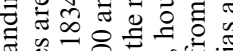

.

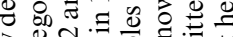

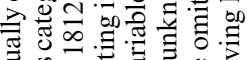

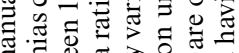

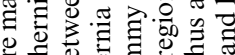

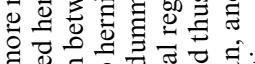

政

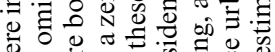

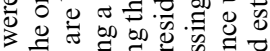

等

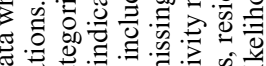

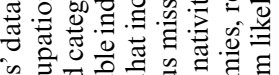

o

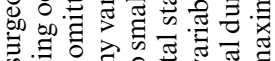

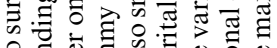

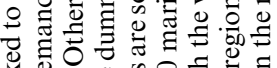
후의.

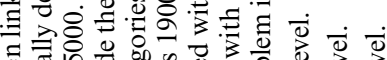

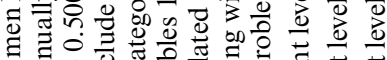

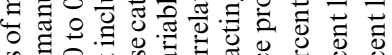

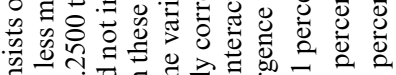

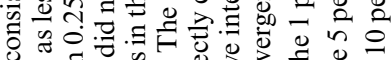

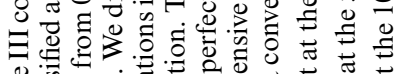
o

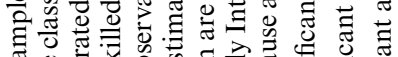

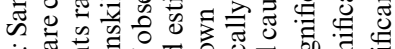

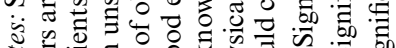

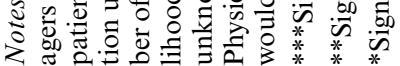


from chronic conditions." This difficulty applies to the mortality measure as well, because mortality can be viewed as the flip side of life expectancy. Calorie intake, height, and BMI are measures of past and current nutritional status and thus reflect demands made upon the body, including those of disease, labor, and even climate (Costa 1996). Yet those are indirect measures of disabilities, and they do not always have strong predictions on the prevalence of each condition. Zero-one disease indicators are interpreted as probabilities of contracting diseases. However, they do not contain information on the severity of each disease, and they do not reflect attitudinal bias that can affect pension compensation, as found in Blanck (2001).

This paper is a first step to construct a more sophisticated chronic disability index from comprehensive medical records and to use this index to forecast the labor supply of older men. We narrowed the scope of this first step by focusing on hernias, a chronic disability that could be extremely debilitating in its later development. We captured the severity of hernias by quantifying descriptions in all symptoms: subtype, location, size, and morbidity. Previous studies (Blanck 2001; Song 2000) show that hernia ratings matched hernia severity under each symptom. In particular, patients who had hernias of the more morbid kind received higher ratings and the ratings were consistent across time and states. One implication from those studies is that instead of using symptoms as health indicators in the retirement study, we could replace symptoms with hernia ratings. The ratings variable is a fraction with the denominator being the maximum scale assigned to the most severe hernias, and the numerator being the scale assigned to a particular hernia patient. Alternatively, we could directly incorporate all symptoms in the labor participation regressions. The inconvenience with this alternative is that the regressions become cumbersome. Each symptom enters the regressions via a set of categorical dummies. For example, there can be three categorical dummies representing hernia location: single hernia, double hernias, and location nonspecified or nonclassified. The number of right-hand-side variables can easily go up as we deal with multiple symptoms.

We find weak evidence of the influence of hernias on the labor force participation of the Civil War veterans, controlling for a general health measure (BMI) and demographic characteristics. Age was a highly significant factor in the labor force participation of older veterans. Consistent with the literature (e.g., Costa 1998; Kanjanapipatkul, ch. 9 in this volume), we find monthly pension award to be a significant predictor for retirement. Every one-dollar increase in the monthly pension raises the odds of retirement by almost 1 percent. The observed income effect applies to all recruits in our sample. We did not find an additional income effect on retirement among hernia patients. Everything else being constant, patients in more manually demanding occupations were equally likely to retire as patients in less manually demanding occupations, even though the latter had, on average, higher 
pay. There existed regional effects on retirement for veterans in the West and Midwest regions, relative to those residing in the Northeast region. Farmers and farm managers living in the West or the Midwest were more likely to retire, perhaps because of the lack of labor market alternatives. We obtain consistent results using a sample of men with hernias versus those without hernias but with other disabilities, a sample of men with hernias versus healthy men, and a subsample of men linked to surgeons' data in 1900 manually demanding occupations.

The Pension Bureau defined disability as the incapacity to perform manual labor. The interpretation of "manual labor" expanded from tasks that required "severe and continuous exertion" in 1862 to include "lighter kinds of labor which require education and skill" in 1872 (Glasson 1918, 131). Recruits in our 1900 and 1910 snapshots benefited from a liberal concept of disability, because both more and less manually demanding occupations fit the 1872 interpretation of manual labor. Despite the more favorable definition of disability over time in the pension system, we did not find that hernias influenced labor force decisions. There are two possible explanations for this result. First, what the pension surgeons (or even modern medical practice) believes to be debilitating, as in the case of hernias, may in fact be historically only discomforting. As a result, retirement was not much influenced by this condition. Second, older veterans in our sample endured hernias as long as the hernias did not pose a mortal threat. In this case, contracting hernias and the worsening of hernias would not cause a reduction in earnings from exiting the labor force - but they would induce a reduction in welfare from the disutility of coping with the pain and possibly from rising medical costs.

\section{Appendix}

\section{Standardization of Diagnoses}

Of the disease variables in the Surgeons' Certificates, hernia variables were among the most robust because the clinical diagnosis of hernias has not changed significantly since the nineteenth century. This allowed interpretation and standardization of the hernia findings without confounding issues, such as differences in medical knowledge and medical language. Among hernia variables, three were chosen for their clinical significance: the anatomic location of the hernia (h_knd); the characteristics of the hernia (h_cls); and the size of the hernia (h_siz).

After the initial transcription and classification of the free-form exam findings into disease variables, finer classification was performed using disease outlines. These outlines contained a multilevel system for classifying 
the many disease observations into a workable and clinically relevant number. At the base of the outline for each variable was the answer class (AC), which contained the major medical finding. Two supplemental categories added more detailed information to the AC. The middle modifier (MM) contained anatomic or descriptive information while the severity modifier (SM) contained severity information. Furthermore, the other variations in spelling, word orientation, and synonyms could be coded with a similar description. This compacted the free-form observations into a few clinically relevant and easily workable categories. Two special AC codes were created for ambiguous data. When the medical description by the Pension Bureau surgeons indicated the presence of an abnormal exam finding or disease, but the specific finding or disease was indeterminate, the observation would be coded as unspecified. When the observation was too vague for medical interpretation or significance, it was coded as unclassified. Table 10.2 demonstrates the standardization process with examples under each diagnostic dimension.

\section{Disability Ratings}

In estimating the overall degree of disability from having a hernia or hernias, two variables may be indicative. The first variable is a nominal dollar amount increasing with the severity of hernias. The second candidate is the ratio variable referred to as the hernia disability rating, where the denominator is the maximum severity of hernias and the numerator is the severity of hernias observed in a patient. The nominal pension amount is unattractive to use as a hernia disability index for four reasons: First, there is a large number of missing observations in this variable (out of 6,395 patient-exam pairs, only 1,311 are nonmissing). Second, the nominal amount depended on military rank. Third, the nominal amount depended on various versions of pension provisions. Fourth, the nominal amount attributed to hernias is highly correlated with the overall dollar amount of pension granted to a recruit. Since we use the overall monthly pension award as a proxy for income, including the dollar award corresponding to hernias as well would contaminate the income proxy. Because of those shortcomings, we used the ratio variable, our second candidate. ${ }^{21}$

The ratio variable is referred to as the disability rating. For example, hernia was considered a disability less than the third grade. Based on the 1873 Consolidation Act, ${ }^{22}$ for a private, a single inguinal hernia of a minor protrusion translated to a disability rating of $6 / 18,{ }^{23}$ a double inguinal hernia of a minor protrusion translated to $10 / 18$, and a single femoral hernia trans-

21. For examples of disability dollar compensations, see Sanders (2000).

22. For a detailed description of the history of pension laws, see Costa (1998, appendix A).

23. Examples are taken from the same sources given in note 5 . 
lated to $10 / 18$. Within the same disability category, the rating unambiguously reflected a surgeon's belief about a patient's disability that is independent of military rank and pension-law updates. ${ }^{24}$

\section{Reliability of Surgeons' Reports}

There have been speculations that the examining surgeons appointed by the Pension Bureau to assess the degree of disability of pension claimants had been biased in their medical judgment. In particular, the surgeons were suspected of exaggerating the symptoms and granting higher disability ratings to veterans, therefore putting an additional strain on the already astronomical Civil War pension costs. Blanck (2001) studied the correlation between an individual symptom under a particular disability and the rating value. ${ }^{25} \mathrm{He}$ found that in general, there was a significant positive correlation between a "yes" answer to a particular symptom and the rating value, and there was a significant negative correlation between a "yes" answer to a particular symptom and the granting of a zero rating that corresponded to no pension. This result shows that there was a reasonable mapping from a symptom to a rating. However, this result does not prove that surgeons were unbiased in examinations, because they could have exaggerated the symptoms to justify asking for larger ratings. Song (2000) tested the claim that the examining surgeons intentionally skewed the disability severity measure of Civil War veterans. She found a close association between the surgeons' ratings and the pension applicants' symptoms in the case of hernias. Furthermore, she found that this association does not change over time and among states with different political party majority votes. This result indicates that surgeons who served for different pension boards and who served during different time periods followed the same examination rule and made consistent medical judgments. She concluded that the Pension Board had administered the UA pension program in a fair manner and that the examining surgeons had carried out their duties accurately.

The finding of a close association between the hernia disability ratings and the hernia symptoms is valuable for our study. Instead of sorting

24. Consider a private and a lieutenant, both of whom had hernia disability ratings equivalent to 0.5000 . A lieutenant would receive a much higher dollar amount (say, $\$ 15$ per month out of the $\$ 30$ maximum total) while a private would receive only $\$ 4$ per month out of the $\$ 8$ maximum total. Regardless of a higher nominal pension received by the lieutenant, both men were judged by the surgeons to be equally disabled from hernias. New laws might increase dollar amounts of pensions for the same disability ratings, but in the case of hernia, they barely altered the ratings themselves. It is because of the unique meaning of the hernia rating variable that we deem it an appropriate index to measure the severity of this disability.

25. See Blanck (2001, appendix 2). He used disease screen variables for the correlation analysis. For example, under the cardiovascular screen, doctors were asked to give yes or no answers to the following symptoms: palpitations; murmurs; dilation, displacement, or enlargement; anasarca, dropsy, edema, or puffiness; cyanosis; dyspnoea; arteriosclerosis; or circulation impairment. 
through numerous symptoms, we can rely on a single variable, the hernia disability ratings, to provide us with an unbiased measure of hernia severity.

\section{References}

Abramson, J., J. Gofin, C. Hopp, A. Makler, and L. Epstein. 1978. The epidemiology of inguinal hernia: A survey in western Jerusalem. Journal of Epidemiology and Community Health 32 (1): 59-67.

Bassini, E. 1889. New operative method for the radical cure of inguinal hernias (in Italian). Atti del Congressa dell' Associazione Medica Italiana 2:179-82.

Baxter, J. 1875. Introduction. In Statistics, medical and anthropological: Provost Marshall General's Bureau, records of the examinations for military service in the armies of the United States during the late War of the Rebellion of over a million recruits, drafted men, substitutes, and enrolled men. Washington, D.C.: GPO.

Blanck, P. D. 2001. Civil War pensions and disability. Ohio State Law Journal 62:109-249.

Blanck, P. D., and C. Song. 2001. "With malice toward none; with charity toward all": Civil War pensions for native and foreign-born Union Army veterans. Journal of Transnational Law and Contemporary Problems 11 (1): 1-76.

Blau, D., and D. Gilleskie. 2001. Retiree health insurance and the labor force behavior of older men in the 1990s. Review of Economics and Statistics 83 (1): 6480.

Bound, J., M. Schoenbaum, T. Stinebrickner, and T. Waidmann. 1999. The dynamic effects of health on the labor force transitions of older workers. Labour Economics 6 (2): 179-202.

Bull, W. 1890. On the radical cure of hernia, with the results of one hundred and thirty-four operations. Trans American Surgical Association 8:99-117.

Center for Population Economics. 1998. Public use tape on the aging of veterans of the Union Army. Chicago: University of Chicago, Graduate School of Business, Center for Population Economics.

Chan, S., and A. Stevens. 2001. Job loss and employment patterns of older workers. Journal of Labor Economics 19 (2): 484-521.

Cheek, C. M., M. I. Williams, and J. R. Farndon. 1995. Trusses in the management of hernia today. British Journal of Surgery 82:1611-13.

Coile, C., and J. Gruber. 2000a. Social Security incentives for retirement. NBER Working Paper no. 7651. Cambridge, Mass.: National Bureau of Economic Research.

2000b. Social Security and retirement. NBER Working Paper no. 7830. Cambridge, Mass.: National Bureau of Economic Research.

Coley, W., W. Keen, and J. DaCosta (eds.). 1910. Surgery, its principles and practice. Philadelphia: W. B. Saunders.

Cooper, A. 1804. The anatomy and surgical treatment of inguinal and congenital hernia. London: T. Cox.

1807. The anatomy and surgical treatment of crural and umbilical hernia. Part II. London: Longman, Hurst, Rees, and E. Cox.

Costa, D. 1993. Height, weight, wartime stress, and older age mortality: Evidence from the Union Army records. Explorations in Economics History 30:424-49. 
1996. Health and labor force participation of older men, 1990-1991. Journal of Economic History 56 (1): 62-89.

. 1998. The evolution of retirement: An American economic history 1880-1990. Chicago: University of Chicago Press.

2002. Changing chronic disease rates and long-term declines in functional limitation among older men. Demography 39 (1): 119-37.

2003. Understanding mid-life and older age mortality declines: Evidence from Union Army veterans. Journal of Econometrics 112 (1): 175-92.

Costa, D., and R. Steckel. 1997. Long-term trends in health, welfare, and economic growth in the United States. In Health and welfare during industrialization, eds. Richard H. Steckel and Roderick Floud. Chicago: University of Chicago Press.

Cutler, D., and B. Madrian. 1998. Labor market responses to rising health insurance costs: Evidence on hours worked. RAND Journal of Economics 29 (3): 509-30.

Dwyer, D., and O. Mitchell. 1999. Health problems as determinants of retirement: Are self-rated measures endogenous? Journal of Health Economics 18 (2): 173-93.

Fogel, R. 1993. New sources and new techniques for the study of secular trends in nutritional status, health, mortality, and the process of aging. Historical Methods 26 (1): 5-43.

2000. Public use tape on the aging of veterans of the Union Army: Military, pension, and medical records, 1860-1940. Version M-5. Chicago: University of Chicago, Graduate School of Business, Center for Population Economics.

Glasson, W. H. 1918. Federal military pensions in the United States. New York: Oxford University Press.

Gustman, A., and T. Steinmeier. 2000. Retirement outcomes in the Health and Retirement Study. Social Security Bulletin 63 (4): 57-71.

Haines, M., L. Craig, and M. Weiss. 2000. Development, health, nutrition, and mortality: The case of the "antebellum puzzle" in the United States. NBER Working Paper no. H130. Cambridge, Mass.: National Bureau of Economic Research.

Halsted, W. 1889. The radical cure of hernia. Johns Hopkins Bulletin 1:12-13.

Hesselbach, F. 1806. Anatomic-surgical treatise on the origin of inguinal ruptures (in German). Wurzburg: Baumgartner.

- 1814. Latest anatomic-pathologic investigations concerning the origin and progress of inguinal and femoral ruptures (in German). Wurzburg: Staheliano.

Iason, A. 1941. The incidence of hernia in man. In Hernia, 156-79. Philadelphia: Blakiston.

Kemp, T. R. 1990. Community and war: The Civil War experience of two New Hampshire towns. In Toward a social history of the American Civil War, ed. Maris A. Vinovskis. Cambridge: Cambridge University Press.

Law, N. W., and J. E. Trapnell. 1992. Does a truss benefit a patient with inguinal hernia? British Medical Journal 304:1092.

Lee, C. 1998. Long-term unemployment and retirement in early-twentieth-century America. Journal of Economics History 58 (3): 844-56.

Lichenstein, I. 1987. Herniorrhaphy: A personal experience with 6,321 cases. American Journal of Surgery 153 (6): 553-59.

Margo, R. A. 1993. The labor force participation of older Americans in 1900: Further results. Explorations in Economic History 30 (4): 409-23.

McVay, C. 1948. Inguinal and femoral hernioplasty: Anatomic repair. Archives of Surgery 57:524-30.

Mitchell, O., and J. Phillips. 2000. Retirement responses to early Social Security benefit reductions. NBER Working Paper no. 7963. Cambridge, Mass.: National Bureau of Economic Research. 
Ponka, J. 1980. Hernias of the abdominal wall. Philadelphia: W. B. Saunders.

Ransom, R. L., and R. Sutch. 1986. The labor of older Americans: Retirement of men on and off the job, 1870-1930. Journal of Economic History 46:1-30.

Riley, J. C. 1991. Working health time: A comparison of preindustrial, industrial, and postindustrial experience in life and health. Explorations in Economic History 28:169-91.

Rubenstein, R., S. Beck, and K. Lohr. 1983. Conceptualization and measurements of physiologic health for adults. Santa Monica, Calif.: RAND.

Rutkow, I. 1998. A selective history of groin hernia surgery in the early-nineteenthcentury." Surgical Clinics of North America 78 (6): 921-40.

Sanders, Matthew. 2000. History of the Civil War pension laws. Appendix 12 in Public use tape on the aging of veterans in the Union Army: Military, pension, and medical records, 1860-1940. Data user's manual, by R. W. Fogel. Chicago: University of Chicago, Graduate School of Business, Center for Population Economics.

Scarpa, A. 1809. Hernia, anatomic-surgical notes (in Italian). Milan, Italy: dalla Reale Stamperia. 1821. Perineal hernias (in Italian). Pavia, Italy: Pietro Bizzoni.

Shearburn, E., and R. Myers. 1969. Shouldice repair for inguinal hernia. Surgery 66 (2): 450-59.

Song, C. 1999. Obtaining years of birth and cleaning exam ages in the Union Army Military and Surgeons' Certificates data sets. University of Chicago, Center for Population Economics. Unpublished manuscript.

2000. Justice or politics: New evidence on surgeons' performance during the United States Civil War pension process. University of Chicago, Center for Population Economics. Unpublished manuscript.

Spraycar, Marjory (ed.). 1995. Stedman's medical dictionary. 26th ed. Baltimore, Md.: Williams and Wilkins.

U.S. Bureau of Census. 1989. Historical statistics of the United States, colonial times to 1970. Part 1. Washington, D.C.: GPO.

Waaler, H. T. 1984. Height, weight, and mortality: The Norwegian experience. Acta Medica Scandinavica 679 (Supplement): 1-56.

Welsh, D., and M. Alexander. 1993. The shouldice repair? Surgical Clinics of North America 73 (3): 451-69. 